\title{
Review Article \\ Chronic Stress and Glucocorticoids: From Neuronal Plasticity to Neurodegeneration
}

\author{
Sheela Vyas, ${ }^{1}$ Ana João Rodrigues, ${ }^{2,3}$ Joana Margarida Silva, ${ }^{2,3}$ Francois Tronche, \\ Osborne F. X. Almeida, ${ }^{4}$ Nuno Sousa, ${ }^{2,3}$ and Ioannis Sotiropoulos ${ }^{2,3}$ \\ ${ }^{1}$ Laboratory of Gene Regulation and Adaptive Behaviors, Department of Neuroscience Paris Seine, INSERM U1130, \\ CNRS UMR 8246, Université Pierre et Marie Curie, Paris Cedex 05, France \\ ${ }^{2}$ Life and Health Sciences Research Institute (ICVS), School of Health Sciences, University of Minho, \\ Campus de Gualtar, 4710-057 Braga, Portugal \\ ${ }^{3} I C V S / 3 B$ 's-PT Government Associate Laboratory, Guimarães, Braga, Portugal \\ ${ }^{4}$ Max Planck Institute of Psychiatry, Kraepelinstrasse 2-10, 80804 Munich, Germany \\ Correspondence should be addressed to Sheela Vyas; sheela.vyas@upmc.fr and Ioannis Sotiropoulos; ioannis@ecsaude.uminho.pt
}

Received 6 November 2015; Accepted 31 January 2016

Academic Editor: Inmaculada C. Ibañez

Copyright (C) 2016 Sheela Vyas et al. This is an open access article distributed under the Creative Commons Attribution License, which permits unrestricted use, distribution, and reproduction in any medium, provided the original work is properly cited.

Stress and stress hormones, glucocorticoids (GCs), exert widespread actions in central nervous system, ranging from the regulation of gene transcription, cellular signaling, modulation of synaptic structure, and transmission and glial function to behavior. Their actions are mediated by glucocorticoid and mineralocorticoid receptors which are nuclear receptors/transcription factors. While GCs primarily act to maintain homeostasis by inducing physiological and behavioral adaptation, prolonged exposure to stress and elevated GC levels may result in neuro- and psychopathology. There is now ample evidence for cause-effect relationships between prolonged stress, elevated GC levels, and cognitive and mood disorders while the evidence for a link between chronic stress/GC and neurodegenerative disorders such as Alzheimer's (AD) and Parkinson's (PD) diseases is growing. This brief review considers some of the cellular mechanisms through which stress and GC may contribute to the pathogenesis of AD and PD.

\section{Introduction}

Stress is broadly defined as an actual or anticipated threat of well-being or disruption of organism homeostasis [1]. Although the sensing and reaction to stress evolved to promote adaptation, modern workstyles and lifestyles represent challenges that render individuals susceptible to physical and mental disorders [2-5]. Multiple factors influence an individual's ability to cope with stress, for example, early life experiences, gender, or personality traits. Both vulnerability and resilience may be determined by genetic and epigenetic (gene environmental interactions) background [5-9].

Since the discovery of the communication between hypothalamus and pituitary in early 70 s that opens a new window in our understanding of the brain-body communication, there are plethora of studies describing the high biological significance of stress and its responses which enables various adaptive processes to changing conditions. The most easily measureable and critical physiological response to stress involves the release of glucocorticoids (glucocorticoids, GCs). These hormones are synthesized and secreted into systemic circulation from the adrenal glands following stimulation by the anterior pituitary hormone adrenocorticotropic hormone (ACTH) [1]. The release of $\mathrm{ACTH}$ itself is increased in response to the secretion of corticotropin-releasing hormone (CRH) and arginine vasopressin (AVP) from neurons in the hypothalamic paraventricular nucleus (PVN). Together, the hypothalamus, pituitary, and adrenal glands constitute the so-called hypothalamo-pituitary-adrenal (HPA) axis, which plays an essential role in the adaptive response to psychogenic (e.g., fear) and physical (e.g., cellular lesion or pathogen invasion) stressors. The adaptive responses that are initiated by GCs occur in multiple tissues and involve alterations in numerous 
physiological (e.g., metabolic, cardiovascular, and immune) as well as behavioral (e.g., emotion, cognition, and motor) processes [1,10-12]. Normally, GC-driven negative feedback mechanisms at the different levels of the HPA axis serve to normalize GC secretion and restore homeostasis; however, and depending on the type, duration, and intensity of the stressful stimulus, GC hypersecretion may persist and become a potential threat for health [1].

There is now abundant evidence that GCs can exert profound modulatory effects on a variety of brain functions from early development through to late life [12]. Their actions are mediated by two receptors: the mineralocorticoid receptor (MR) and glucocorticoid receptor (GR), which belong to the superfamily of nuclear receptors that act as transcription modulators $[13,14]$. In the brain, GR is ubiquitously expressed, whereas MR expression is more restricted to just a few structures (hippocampus, locus coeruleus, amygdala, prefrontal cortex, and nucleus of the solitary tract, as well as PVN neurons). MR is also present in nonneuronal cells, namely, in glia and epithelial cells of the choroid plexus and ependyma [15].

Binding assays using ${ }^{3}[\mathrm{H}]$ corticosterone have shown the MR has a 10-fold higher affinity $\left(K_{d}=0.5 \mathrm{nM}\right)$ for GC compared to GR $\left(K_{d}=5 \mathrm{nM}\right)$, which means that, at basal GC levels, MR is occupied and activated [16] whereas GR is only activated when GC levels reach a certain level, for example, during the circadian peak of GC secretion and during stress [17]. Importantly, brain MR and GR both respond to the same endogenous ligand (cortisol in humans and larger mammals, corticosterone in rodents); further, MR and GR were reported to colocalize in the same pyramidal and granular neurons of the hippocampus [17]. Given the GR and MR colocalization and relatively small difference in their affinity for endogenous GCs, the question arises as to whether they regulate distinct genes and/or coregulate transcription by heterodimerization. Heterodimerization of GR and MR was shown with high concentration of GC (stress level) in the nuclei of cultured hippocampal neurons. Moreover, evidence suggests that their cellular responses through regulation of distinct gene expression (as homodimers) depend strongly upon specific recruitment of coregulators $[18,19]$.

Synthetic GCs (e.g., dexamethasone, methylprednisolone) are routinely used in clinical situations due to their powerful anti-inflammatory and immunosuppressive actions. However, a growing body of evidence suggests that high GC exposure in early life can adversely program the HPA axis and increase the susceptibility to develop metabolic, neuropsychiatric, and neurodegenerative disorders $[5,20$, 21]. In addition, there is now ample experimental evidence where elevated GC levels and prolonged exposure to stressful conditions induce structural remodeling of neurons with synaptic loss as well as alterations in glial functions, which are frequently maladaptive [22]; see also Figure 1 . In this brief review we discuss some of current knowledge about cellular targets and mechanisms through which stress and altered GC levels trigger changes in the brain that may lead towards the development and progression of neurodegenerative pathologies such as Alzheimer's (AD) and Parkinson (PD) disease.

\section{From Stress-Driven Brain Programming to Neurodegenerative Pathologies}

In addition to nongenomic mechanisms that are still incompletely identified [23], chronic stress and GC levels most likely influence neuronal function and connectivity by activating GR-mediated transcription. GRs are normally located in the cytoplasm in association with chaperone proteins such as the heat shock proteins $\mathrm{Hsp} 90$ and 70 and the immunophilins FKBP51 and FKBP52. Upon GC binding, conformational change of the GR-chaperone complex results in nuclear translocation of the GR [24, 25]. In the nucleus, GR binds to specific regions of DNA, which possess glucocorticoid response elements (GRE) within the promoters of target genes, leading to cell-type and context-dependent gene expression [26-28]. Transcriptional regulation by GR may occur by (a) direct binding of GR homodimers to GRE within DNA sequences to stimulate transcription, for example, mitogen-activated protein kinase phosphatase-1 gene; (b) direct binding to negative GRE elements to repress transcription; the gene encoding the prohormone from which ACTH is derived (proopiomelanocortin, $P O M C$ ), $C R H$, and the $C R H$ receptor genes are examples of negatively regulated genes; and (c) trans-repression or "tethering," that is, association with other transcriptional factors that inhibit the transcriptional activity of GR. In the brain, identification of GRmodulated genes is difficult due to the anatomical complexity and cellular heterogeneity. Nevertheless, transcriptomic studies in the hippocampus have identified functional classes of GR target genes which include genes coding for neurotransmitter catabolism, neurotrophic factors and their receptors, signal transduction, energy metabolism, and cell adhesion [29].

In addition to altering gene expression, growing evidence suggests that epigenetic mechanisms represent a means through which stress and GCs can leave longlasting "memories" of past experiences which, in turn, contributes to shaping the organism's physical and mental health trajectory $[21,30,31]$; see Figure 1 . Broadly, epigenetics refers to stable changes in the regulation and/or function of DNA, RNA, and/or proteins that do not involve alterations of their primary sequences. Two well-known examples of epigenetic marks induced by environmental stimuli (e.g., stress) are DNA methylation and histone modification. The first evidence of epigenetic programing in the brain by early life adversity showed that poor maternal care in rats leads to methylation of exon $1_{7}$ in the $G R$ promoter, being accompanied by aberrant behaviors and altered HPA axis responses during adulthood [32, 33]. Subsequently, similar mechanisms were reported in humans who had experienced childhood adversity [34] and in infants born to depressed mothers [35]. The earlier studies in rats were replicated in mice in paradigms of prenatal GC exposure and early postnatal stress; we showed that these pre- and postnatal manipulations resulted in epigenetic modifications of the promoters of neurotransmitter (dopamine receptor 2) [36], GR, and various GR target genes $[37,38]$ with long-lasting maladaptive behavioral consequences. 


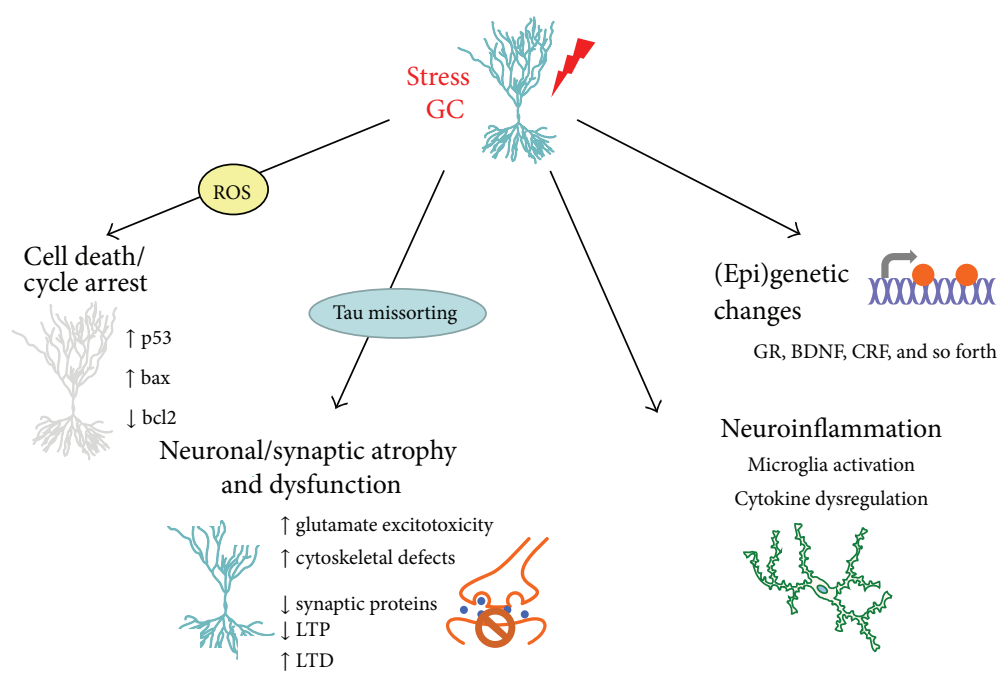

Figure 1: Cellular targets and actions of chronic stress mediated by glucocorticoid receptors. This schema depicts some cellular targets and mechanisms that are targeted by glucocorticoids (GCs), whose actions are mediated by glucocorticoid receptors (GR). GCs are secreted under conditions of stress; neuronal damage and brain pathologies are a common consequence of persistently elevated GC secretion. GC can trigger mitochondrial dysfunction and the apoptotic machinery, as well as cell cycle arrest and cell death. In addition, stress/GC may induce neuronal atrophy and synaptic dysfunction/loss by stimulating hyperphosphorylation of the cytoskeletal protein Tau, thus disturbing the integrity of the cytoskeleton and missorting Tau at synapses. Together, these latter events may eventually result in the degradation of synaptic proteins and receptors and consequently, synaptic plasticity. Stress and GC are also established as modulators of microglial activation and neuroinflammatory processes. Lastly, accumulating evidence indicates that stress and GC can influence neuronal structure and function through epigenetic mechanisms.

Recent studies also suggest that early life events (e.g., intrauterine infections, maternal stress, and poor maternal and perinatal nutrition) may play a role in the onset of Alzheimer's disease (AD), an age-related neurodegenerative disorder characterized progressive memory and cognitive deficits [39]. From this perspective, AD is probably not determined by a single etiologic factor but results from the interplay between genetic and environmental factors throughout life, possibly explaining why monozygous twins can be discordant for AD. Albeit this is still controversial and the literature is sparse, it has been suggested that adverse events in early life, for example, maternal stress and poor maternal and perinatal nutrition, can potentially predispose eventually to $\mathrm{AD}$ through epigenetic programing of specific genes/pathways related to AD neurodegeneration. For example, maternal separation for the first 3 weeks of rodent life is shown to result in increase of AD cellular pathways (e.g., APP misprocessing and Tau hyperphosphorylation; see below) followed by synaptic and neuronal damage as well as cognitive deficits in adulthood [40] suggesting the potential impact of early-life stress exposure to the precipitation of $\mathrm{AD}$ neurodegeneration later in life. While most current research on epigenetic mechanisms focuses on DNA methylation, one recent study demonstrated that GC, acting via GR, increase the levels of histone deacetylase 2 (HDAC2), an enzyme regulating DNA expression, in the CK-p25 mouse [41]. In general, how early life stressors reprogram the fetal brain and contribute to late-life development of neurodegenerative disorders (e.g., $\mathrm{AD}$ ) is emerging as an exciting, new research field [42].

Experimental evidence in animal studies indicates that stressful events in early life can impact the etiopathogenesis of another neurodegenerative disorder, Parkinson's disease (PD), which is characterized by both motor and nonmotor symptoms. Depression, anxiety, apathy and interestingly fatigue are common nonmotor features occurring in around 30 to $58 \%$ of patients before the onset of motor symptoms in PD patients. In addition, the prevalence of cognitive impairment in PD ranges from 19 to 36\% [43]. The cellular mechanisms underlying these nonmotor symptoms in PD may share similarities to $\mathrm{AD}$, particularly with respect to the molecular pathways activated by stress.

Maternal separation was reported to exacerbate motor deficits and nigrostriatal lesion in an experimental model of PD [44]. In an interesting study, pups of female animals, exposed to the bacterial endotoxin lipopolysaccharide (LPS) during pregnancy, showed loss of dopaminergic (DA) neurons. Since loss of dopaminergic neurons as well as related motor deficits is a characteristic feature of PD pathology, the above findings suggest that high LPS levels in mothers might interfere with the development of DA neurons in the fetus, thus enhancing susceptibility to PD [45]. Accordingly, developmental stress may represent the first imprint in the brain and accumulatively with later stressful stimuli to affect nigrostriatal neurochemical reserve and precipitate the $\mathrm{PD}$ phenotype [46].

\section{Chronic Stress and GC as a Risk Factor for AD}

$\mathrm{AD}$ is a multifactorial neurodegenerative disorder with complex etiopathology. Besides early life stress (see above), accumulating clinical evidence strongly suggests that chronic 
stress in adulthood as well as elevated GC levels may have a role in the development of $\mathrm{AD}$ pathology and related dementia $[47,48]$. In fact, high levels of cortisol are commonly found in AD patients' plasma, saliva, and/or CSF [49-53]; $\mathrm{AD}$ patients also show higher total daily secretion of cortisol [54]. The potential link between stress/GC and AD described above is strengthened by emerging evidence that stress may advance the age of onset of the familial form of $\mathrm{AD}[47,48,55]$ and that cortisol levels in $\mathrm{AD}$ patients correlate with their memory deficits $[56,57]$ suggesting a role for GC on AD. Nevertheless, in the absence of longitudinal studies it is not clear from the available evidence as to whether elevated GC secretion is a cause or a consequence of $\mathrm{AD}$ disease.

An important brain area in unraveling the interrelationship between stress, elevated GC, and AD pathology is the hippocampus, which is among the first areas affected in $\mathrm{AD}$ patients. Hippocampal lesions in AD brain are not only associated with the deficits in declarative, spatial, and contextual memory but could also be responsible for the suggested HPA axis dysregulation and the subsequent overproduction of GC found in $\mathrm{AD}$ patients due to the inhibitory role that hippocampus exhibits on HPA axis. Indeed, previous studies from our laboratories (and others) have shown that hippocampal neurons are particularly vulnerable to the adverse effects of stress and GC, their effects being manifested as dendritic atrophy and apoptotic cell death [22,58]. Moreover, a large number of studies have shown that stress and elevated GC levels affect neurogenesis in adult brain with subsequent impairments of mood and cognitive behavior [59, 60]. More specifically, both acute and chronic exposure stress reduces adult neurogenesis, affecting hippocampal cell proliferation and, in certain studies, survival of newborns [61, 62]. In addition, administration of corticosterone showed the ability of glucocorticoids to damage neurogenesis in adult brain by inhibiting cell proliferation, differentiation and survival [63] while the deleterious effect of stress and/or corticosterone on neurogenesis is GC-dependent [64]. In a vicious cycle, alteration in neurogenesis of adult brain is recently shown to impact on GC negative feedback on the central elements regulating HPA axis activity $[65,66]$. Moreover, perturbations in adult neurogenesis may also be related to the cognitive deficits associated with $\mathrm{AD}$ whereas contradictory findings support both increases and decreases of neurogenesis in brain of $\mathrm{AD}$ patients and Tg animal models [67]. Here, it is also worthwhile noting that stress and GC interfere with hippocampal-prefrontal cortex (PFC) connectivity [68] and dendritic and synaptic plasticity in the PFC, thus disrupting executive functions [58]. These PFC structural deficits are also likely to have consequences for central regulation of the HPA axis providing another neuroanatomical link between HPA axis dysregulation and subsequent GC hypersecretion and $\mathrm{AD}$ pathology.

\section{Impact of Stress and GC on Neurodegenerative Mechanisms of AD}

At the molecular level, AD pathology is characterized by amyloid beta $(\mathrm{A} \beta)$ that forms deposits (senile plaques) and hyperphosphorylated forms of the cytoskeletal protein Tau that aggregate into neurofibrillary tangles (NFT) [6971]. $\mathrm{A} \beta$ is the proteolytic product of a large transmembrane protein called amyloid precursor protein (APP), which is sequentially cleaved by $\beta$-secretase (BACE-1) and $\gamma$-secretase (a complex of enzymes) to generate the production of $A \beta$; this cellular pathway is often called APP misprocessing. Many studies have demonstrated that the products of APP misprocessing trigger neuropathological processes associated with $\mathrm{AD}$ such as synaptic malfunction (including impairment of long-term potentiation), neuronal atrophy and synaptic disintegration and loss [72] as well as mitochondrial dysfunction, oxidative stress, and glial activation [73].

Although still a subject of debate, several studies suggest that $\mathrm{A} \beta$ also triggers the abnormal hyperphosphorylation of Tau, NFT formation, and neuronal loss. Moreover, cumulative evidence suggests that the detrimental effects of $\mathrm{A} \beta$ are abolished in Tau-KO mice, highlighting the essential mediatory role of Tau protein in the neuro- and synaptotoxic effects of $A \beta$ [73-77]. Further support for an essential role of Tau in the establishment of AD pathology derives from clinical findings that have consistently shown that the cognitive deficits in $\mathrm{AD}$ patients correlate better with NFT rather with $A \beta$ deposition per se. Moreover, Gómez-Isla et al. [78] demonstrated a strong correlation between neuronal loss in the cerebral cortex and increased NFT burden with disease progression; no such correlation was found with $\mathrm{A} \beta$. In addition, the reduction of hippocampal volume in $\mathrm{AD}$ patients correlates better with CSF levels of phosphorylated Tau than with those of $A \beta$ [79].

The evidence of a causal relationship between stress/GC and $\mathrm{AD}$ includes that from studies showing that either high GC levels and/or stress increase the production of $A \beta$ and exacerbate memory deficits in transgenic mouse models of AD [80, 81]. Specifically, chronic immobilization stress in transgenic mice expressing the amyloid precursor protein (APP) V717ICT-100 (a mutation which results in aggressive early onset $\mathrm{AD}$ ) accelerates the appearance of extracellular $\mathrm{A} \beta$ deposits and worsens memory deficits. Similar findings were obtained in vivo when young (prodromal) $3 \mathrm{XTg}-\mathrm{AD}$ mice were treated with the synthetic GC, dexamethasone [80]; the same authors also reported dexamethasone-induced APP misprocessing in the N2A cell line, a finding matched by our own observations in PC12 cells [82]. Further, Green et al. demonstrated that GCs upregulate the transcription of $A P P$ and $\beta$-secretase, whose promoters contain a glucocorticoid response element (GRE) [80]. Consistent with the above, our studies in middle aged rats showed that stress and chronic GC drive APP processing towards the generation of $\mathrm{A} \beta$ and its precursor molecule (C99), both of which have neurotoxic and cognition-impairing properties [83] (see also Figure 1). The latter changes were accompanied by increases in the levels of $\beta$-secretase (BACE-1) and Nicastrin, a protein found in the $\gamma$-secretase complex. Further experiments that attempted to mimic intermittent stressful events that may exert cumulative effects over the lifetime indicated that GC potentiate the APP misprocessing pathway in previously stressed rats receiving A $\beta$-infusions [83] (see Figure 2). 


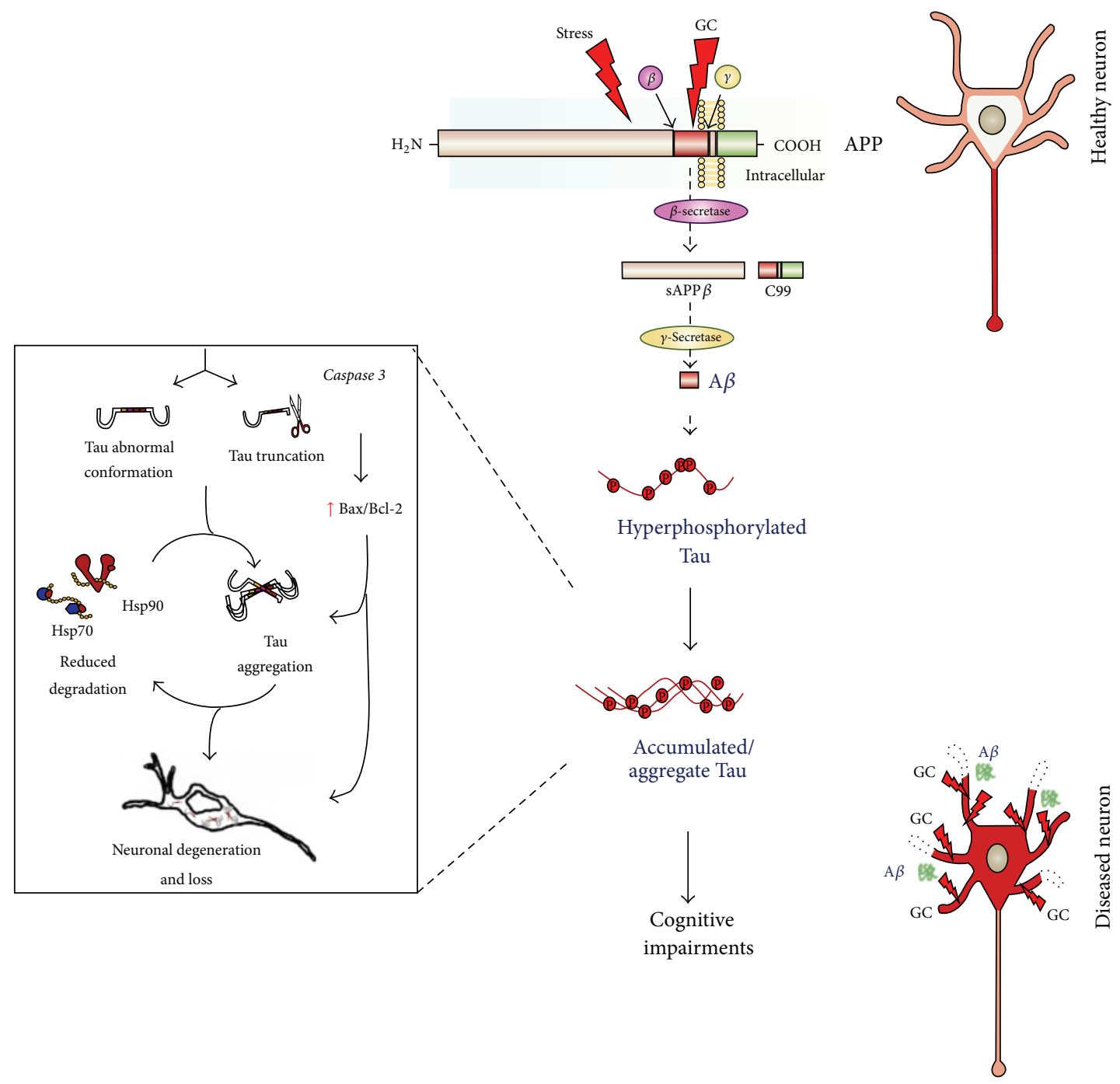

FIGURE 2: Proposed model through which chronic stress and glucocorticoids (GCs) may contribute to Alzheimer disease (AD) pathology. The model illustrates how chronic stress and high GC levels can trigger AD pathology; the figure is based on experimental evidence obtained in cellular and animal models of AD. Extended exposure to stress/high GC levels activates the amyloidogenic pathway of amyloid precursor protein (APP). This so-called misprocessing of APP involves the sequential cleavage of APP by $\beta$ - and $\gamma$-secretases, resulting in the generation of toxic amyloid $\beta(\mathrm{A} \beta)$. Subsequently, the cytoskeletal protein Tau, which is mainly localized in axons (red in the representation of a healthy neuron), becomes aberrantly hyperphosphorylated, catalyzed by glycogen synthase kinase (GSK3 $\beta$ ) and/or cyclin-dependent kinase 5 (CDK5). Hyperphosphorylated Tau is trafficked to, and accumulates in, the somatodendritic compartment, where it oligomerizes and forms insoluble aggregates (red in the diseased neuron). In addition, the abnormal conformation adopted by Tau and caspase 3-mediated truncation of Tau is accompanied by dysregulation of the molecular chaperones Hsp90 and Hsp70, which normally serve to promote Tau degradation (left panel). This cascade of events causes neuronal atrophy and loss, followed by cognitive impairments.

In addition to triggering the amyloidogenic pathway, high levels of GC and stress can also instigate the aberrant hyperphosphorylation of Tau protein that also characterized AD brain. Among the first reports suggesting a potential connection between GCs and Tau was that from Stein-Behrens et al. [84] who demonstrated that GC exacerbate kainic acidinduced hippocampal neuronal loss with a contemporaneous increase in Tau immunoreactivity. A later study showed that chronic treatment of 3xTg AD mice with dexamethasone leads to the somatodendritic accumulation of Tau in the hippocampus, amygdala and cortex [80].
Supporting those earlier studies, we showed that chronic stress or GC increase the levels of aberrantly hyperphosphorylated Tau in the rat hippocampus and PFC [85] (see Figure 2). Importantly, the hyperphosphorylation occurred at certain Tau epitopes that are strongly implicated in cytoskeletal dysfunction and synaptic loss (e.g., pSer262) $[86,87]$ and hippocampal atrophy (e.g., pThr231) [88] in AD patients. Here, it is pertinent to note that the extent of phosphorylation at Thr231- and Ser262-Tau correlates strongly with severity of memory impairment, speed of mental processing, and executive functioning in $\mathrm{AD}$ patients [89-91]. 
Although chronic stress and GC treatment exert similar, but not identical, effects on individual Tau phosphoepitopes in vivo and in vitro [82], the overall evidence points to GC as the key mediator of the $\mathrm{AD}$-like pathology induced by stress. On the other hand, some studies have suggested a role for at least one other stress-related molecule, namely, corticotrophinreleasing hormone $(\mathrm{CRH})$, as deletion of the $\mathrm{CRH}$ receptor 1 gene in mice was found to block the detrimental effects of stress on Tau phosphorylation $[92,93]$.

As shown at Figure 2, information on the mechanisms underlying stress/GC-induced hyperphosphorylation of Tau is only just beginning to emerge. For example, in vitro experiments indicate that the effects of stress/GC are mediated by glycogen synthase kinase 3 (GSK3) and cyclin-dependent kinase 5 (CDK5), both of which have well-established roles in Tau hyperphosphorylation and the subsequent disruption of microtubules, features seen in the AD brain [82]. We now also know that GC exposure increases Tau accumulation by affecting turnover of the protein by reducing its degradation [82]; the latter appears to result from dysregulation of molecular chaperones (e.g., Hsp90 and Hsp70) that are responsible for Tau proteostasis [94] (see Figure 2). Interestingly, both these heat shock proteins also serve to maintain GR in a high affinity state, suggesting that these proteins may be the point at which GC/GR signaling intersects with the cellular machinery that regulates Tau degradation. Using a transgenic mouse that expresses human P301L-Tau (the most common Tau mutation), we recently showed that chronic stress triggers different aspects of Tau pathology in addition to inducing, its aberrant hyperphosphorylation and aggregation of Tau into insoluble forms [94]. Adding to the mechanistic understanding of stress-driven aggregation of Tau, we also showed that chronic stress enhances caspase 3-mediated truncation of Tau at its C-terminal, leading to an abnormal conformation of Tau in the hippocampus (Figure 2). This truncation-dependent misfolding of Tau into an abnormal conformation is known to facilitate nucleation and recruitment of other Tau molecules into neurotoxic aggregates $[95,96]$ before NFT are formed $[95,97,98]$.

It is interesting to note that chronically elevated GC secretion, usually in response to stress, is a major cause of major depressive illness [99]. In light of the increasing volume of data implicating high GC levels in $\mathrm{AD}$, it is important to consider that epidemiological studies implicate depression as a risk factor for the development of $\mathrm{AD}$; this is supported by the observation that previously depressed subjects have increased amyloid plaque and NFT loads [100]. Different studies have in fact sought to discriminate between subjects undergoing normal aging from those suffering from depression or $\mathrm{AD}$ through the measurement of the various APP cleavage products [101-104]. While much remains to be discovered about the potentially important role of depression in $\mathrm{AD}$ pathology, it is interesting to note that antidepressant drugs, whose actions often involve reductions in GC secretion, inhibit the proteolytic cleavage of APP into amyloidogenic products $[104,105]$.

Lastly, it deserves mentioning that a recent epidemiological study found that the prevalence and incidence of dementia in war veterans suffering from posttraumatic depression (PTSD) is twice as high as that in age-matched PTSD-free subjects [106]. While PTSD is a condition quite distinct from major depression, these findings hint at the important influence lifetime stressful experiences can have on mental health, possibly through epigenetic mechanisms. The findings are also interesting since PTSD patients usually show hypoactivity of the HPA axis (versus hyperactivity in depression), suggesting that just a single-but major stressful-event involving transient GC hypersecretion can have long-lasting neuropathological consequences.

4.1. Inflammation and $A D$ : Role of GCs? Chronic inflammation is one of the central pathological features of $\mathrm{AD}$ with reactive microglia and astrocytes surrounding senile $\beta$-amyloid plaques observed in both postmortem AD brain and animal models $[107,108]$. Evidence from human studies suggests that glial activation is an early event; thus inflammatory markers are present in mild cognitive impairment cases that eventually progress to $\mathrm{AD}$ [109]. Thus proinflammatory cytokines produced by activated glia in response to amyloid fibrils would be expected to activate HPA axis and increase $\mathrm{GC}$ levels. In vitro studies clearly show that $\mathrm{A} \beta$ can be taken up through phagocytosis in microglia and thereafter degraded [110, 111]; thus, in AD setting, microglial likely have a beneficial role early in pathology. However, elevation of proinflammatory cytokines such as IL-1 $\beta$ may also participate in mood disorders such as depression [112] in AD.

The importance of immune-related responses in the emergence of $\mathrm{A} \beta$ burden, tau pathology, and dementia is gaining momentum as molecular comprehension of their actions is increasingly unraveled by human genetic and animal studies. Recent genome-wide association studies have identified variants in at least 16 genes involved in microglia/macrophage functions as risks for developing $\mathrm{AD}$ [113]. Among them, $\varepsilon 4$ allele of $A P O E$ gene is a known strong risk factor, accelerating the age of onset of $\mathrm{AD}$. APOE is produced by both microglia and astrocytes; it regulates not only lipid and $\mathrm{A} \beta$ metabolism but also microglial chemotaxis and proinflammatory cytokine expression [114]. Recently, another strong link was found between variants in TREM2 gene and AD. TREM2 is specifically expressed in myeloid cells where it promotes phagocytosis whilst inhibiting cytokine production [115]. These and most other GWAS genes identified [113] are involved in aberrant microglial/macrophage responses with regard to $\mathrm{A} \beta$ clearance and spread of Tau pathology.

In addition to genetic susceptibility, prolonged exposure of $\mathrm{A} \beta$ affects microglial functions. Thus, crucial microglial functions such as motility and phagocytosis were impaired in APP/PS1 mice [116]; also in these mice the levels of $\mathrm{A} \beta$ receptors (SRA, CD36, RAGE) and $\mathrm{A} \beta$ degrading enzymes (neprilysin, MMP9) were decreased with concomitant increase in proinflammatory cytokines TNF- $\alpha$ and IL$1 \beta$ [117]. Age, a primary risk factor for $\mathrm{AD}$, is also an important contributor to dysfunction of innate immune responses. Microglial dystrophy and fragmentation observed in aging brain [118] occur before the appearance of abnormal Tau suggesting dysfunctional microglia could contribute to appearance of Tau pathology. 
Chronic stress through GCs is known to prime and augment neuroinflammatory processes in the cortex and hippocampus upon subsequent proinflammatory challenges such as LPS $[119,120]$. Peripheral infections and stress are both known to affect the activation state of microglia and in $\mathrm{AD}$ pathology both could have detrimental effects on the functions of microglia. There is little known on how glucocorticoids influence glial functions during prodromal to emergence and progression of $\mathrm{AD}$ pathology. It would be important to understand whether GC through GR has any role in $\mathrm{A} \beta$ degradation in astrocytes or myeloid cells.

\section{Role of Glucocorticoids in Onset and Progression of Parkinson's Disease}

Parkinson's disease (PD) is a complex systemic and progressive neurodegenerative disease associated with both motor and nonmotor symptoms. The cardinal motor symptoms such as akinesia, resting tremor and rigidity mostly arise from preferential and substantial loss of dopaminergic neurons (50-60\%) in the substantia nigra pars compacta (SNpc) with significant dopamine depletion in the sensorimotor striatum. The nonmotor symptoms include olfactory dysfunction and sleep behavior disorder as well as mood changes and cognitive impairment as discussed above. One principle histopathological feature is the presence of Lewy bodies (LBs), which are proteinaceous inclusions containing mainly structurally altered presynaptic protein, alpha-synuclein, which, as recent evidence shows, plays a central role in PD pathology. Alpha-synuclein LB deposition was used by Braak et al. [121] as a principle pathological marker to monitor the progression and severity of PD. PD is believed to originate from olfactory nucleus and autonomic nervous system progressing in an ascending manner to many brain regions such as substantia nigra, striatum, raphe, locus coeruleus, hypothalamic nuclei, hippocampus, amygdala, and cerebral cortex accounting for both motor and nonmotor symptoms [121-123]. Thus, for example, PD patients with cortical LBs also suffer from dementia and visual hallucinations [124].

While several gene mutations have been identified in familial forms of PD, the majority of PD cases are sporadic and of unknown etiology. Nevertheless, significant advances in the last decade on PD genetics, particularly genomewide association, as well as pathophysiological mechanisms in various PD model systems, have contributed much to our comprehension of PD. Cellular processes such as oxidative and nitrative stress, mitochondrial dysfunction, and deregulated intracellular calcium levels as well as damaged proteostasis related to alpha-synuclein aggregation are the most studied and relate to dopamine neurodegeneration [125].

As in AD patients, the HPA axis is likely dysregulated in PD patients. Specifically, previous studies [54, 126-128] including our own work [129] show that plasma cortisol levels are significantly higher in idiopathic PD patients compared to control subjects; however, these high levels do not correlate to disease duration or to L-3,4-dihydroxyphenylalanine (L-DOPA) treatment. Interestingly, the diurnal pattern of cortisol secretion in PD patients, in particular the normally quiescent nocturnal cortisol secretory pattern, is affected [54].

\section{The Neurodegenerative Potential of Altered GC Levels in PD Pathology}

Chronically elevated GC levels in PD patients suggest that HPA regulated-stress responses may impact PD pathology. Indeed, the role of stress was proposed as one of the underlying causes of PD as clinical reports show that stress triggers the appearance of PD symptoms or exacerbates the motor symptoms [130-132]. The role of stress in PD is supported by few experimental studies such as food deprivation and tail-shock and maternal separation aggravate motor deficits in the 6-hydroxydopamine (6-OHDA) PD model (6hydroxydopamine local injections lesions the nigrostriatal pathway) [133]. In combined chronic stress exposure with 6-OHDA lesion, stress was shown to worsen the 6-OHDAdriven motor deficits, aggravate the neurodegeneration of nigrostriatal system, and completely block compensatory recovery of motor tasks [131, 134]. The precise actions of high GC levels in motor control following nigrostriatal lesions are yet not known. Analysis of GR expression in PD brains revealed that GR levels were reduced in the SNpc and augmented in the putamen, compared to age-matched control subjects; similar results were found in MPTP- (1methyl 4-phenyl 1,2,3,6-tetrahydropyridine-) treated mice [129]. GCs are known to profoundly modulate dopaminergic neurotransmission. The role of GC on the limbic arm of the dopaminergic circuitry related to reward and motivation as well as neuropsychiatric diseases has been extensively investigated (see below). Thus, from its known roles in mesolimbic circuitry, it has been postulated that GR also likely affect motor automated or habitual skills of the sensorimotor circuitry in the striatum by influencing NMDA/AMPA receptor functions in D1 and D2 receptormedium spiny neurons (Figure 3 ). Indeed, it has been shown that chronic stress leads to opposing structural changes in the limbic/associative and sensorimotor striatal circuitry with atrophy in the former and hypertrophy of sensorimotor striatum, leading to habit behavior [135]. In addition, the roles of both glucocorticoids and noradrenaline were recently reported in habit memory [136]. It is possible that GRmediated changes in the putamen during the prodromal stage of PD play a role in preventing the appearance of motor symptoms, culminating in dopamine depletion and death of dopaminergic neurons in the substantia nigra.

Altered stress responses most likely play an important role in nonmotor PD symptoms, particularly anxiety, depression, and mild cognitive impairment, which often precede motor symptoms. Interestingly, there is also evidence in PD for lower novelty-seeking and high harm avoidance personality traits with anxiety-associated symptoms $[43,137]$. These observations suggest that, in the initial disease stage, stress-related alterations in GC-GR activity could impact both the motivation/cognitive-associated dopaminergic as well as nondopaminergic (serotonergic and noradrenergic) 


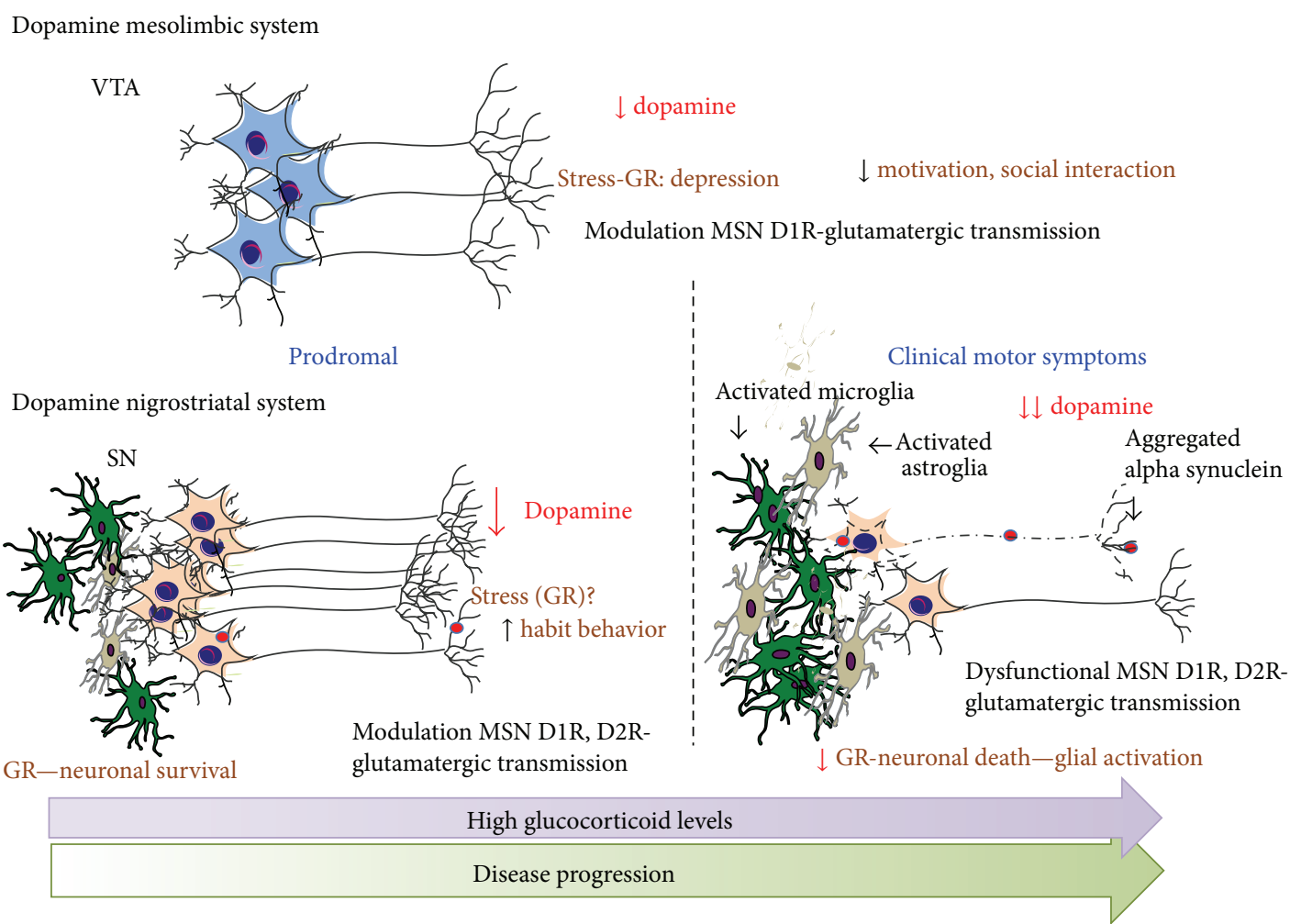

FIgURE 3: Putative impact of elevated GC levels on GR function in nigrostriatal and mesolimbic dopaminergic systems in PD. Stresslevel elevation of GCs may be an early feature of PD, potentially impacting both motor and nonmotor dopaminergic systems. Mesolimbic dopaminergic circuitry is likely affected through structural and functional changes occurring in D1R MSNs. These changes lead to depression and reduced motivation and social interaction which are key prodromal features of PD. Dopaminergic neurons in VTA are relatively spared in PD. In the nigrostriatal system, high levels of GCs initially protect dopaminergic neurons of substantia nigra through dampening the immune responses, namely, mediated by activated microglia and astrocytes. In the putamen, high stress levels of GCs through GR augment habit learning and may act to prevent the appearance of motor symptoms. With disease progression, GR function is affected, leading to chronic glial and immune activation, which exacerbates dopamine neurodegeneration with significant dopamine depletion in the striatum. Changes in GR activity may also affect striatal D1 and D2R MSNs further participating in the appearance of clinical motor symptoms.

neuronal circuitry. This would also implicate dopaminergic neurons in the ventral tegmentum area (VTA), which although relatively spared in PD are well-known to regulate reward and aversion by stress and have been implicated not only in addiction but also depression involving the transcriptional factor CREB and BDNF [138-141]. On the other hand, dorsolateral dopamine neurons in the SN (vulnerable in $\mathrm{PD}$ ) were shown to respond to tasks involving working memory [142]; thus, their demise could explain, in part, the cognitive deficits observed in PD. Studies on the dopaminergic transmission during stress have revealed the complexity of the system. In fact, firing patterns of dopamine neurons in VTA correlated with depressive-like behaviors in mice, although the effect appears to depend on the stress paradigm used to induce the depressive-like behavior [139, 143]. Electrophysiological evidence implicates changes in both D1R and D2R-medium spiny neurons (MSNs) in the ventral striatum [144], but the depressive-behaviors seems to preferentially affect D1R MSNs [145] (Figure 3). Glutamatergic receptors, NMDA and AMPA receptor functions were shown to be also altered in the D1R MSNs, notably NMDARdependent LTD, reduced AMPA/NMDA receptor ratio and increased endocytosis of AMPA receptors [146].

\section{Role of Glucocorticoid Receptors in Inflammation-Induced Neurodegenerative Processes and Nonmotor Symptoms in Parkinson's Disease}

Accumulating evidence points to inflammation resulting from chronic activation of innate and adaptive immune cells as playing an important role in both neurodegenerative processes and in nonmotor symptoms of PD. Using radiolabeled ligand ${ }^{11} \mathrm{C}-\mathrm{PK}-11195$ for translocator protein, Positron Emission Tomography (PET) studies in PD patients revealed an early activation of microglia in many brain regions including basal ganglia and midbrain [147, 148]. Furthermore, postmortem studies as well as analyses of serum and cerebrospinal fluid from PD showed high levels of proinflammatory mediators such as TNF- $\alpha$, IL- $1 \beta$, iNOS, IFN- $\gamma$, and COX-2 [149]. In line with observations in PD patients, presence of inflammatory mediators and glial reactivity in striatum and substantia nigra is a key feature in many of the experimental animal models of PD [150]. Evidence from recent genome-wide studies points to involvement of the immune system in the etiology of idiopathic PD. A number of susceptibility loci identified relate to genes 
expressed in immune cells such as HLA-DQB1, LRRK2 or BST-1 [151, 152]. In addition, identified PD risk factors [such as age, environmental toxins (e.g., heavy metals or pesticides,) traumatic brain injury, and bacterial or viral infections] activate immune responses in periphery and brain.

7.1. GR Regulation of Inflammation Important for Dopamine Neuronal Survival. Activated microglia functioning as innate-immune competent cells are likely involved in releasing the above inflammatory molecules, thereby inducing dopamine neurodegeneration. Indeed, the important role of these proinflammatory mediators in promoting degeneration of dopaminergic neurons of substantia nigra was demonstrated using mice with specific knockout of these genes [153-156]. Many of the proinflammatory mediators found in PD patients are transcriptional targets of GR. The synthetic analogue of GCs, dexamethasone, was shown to attenuate dopamine neuronal loss by precluding activated microglia from releasing toxic inflammatory molecules $[157,158]$. In adrenalectomized mice (lacking endogenous production of GCs), dopamine neuronal loss was augmented following MPTP intoxication indicating that endogenous GCs do play a role in protecting dopamine neurons [159]. Examination of GR in microglia revealed an increase in nuclear localization of GR following MPTP treatment in mice, which coincided with a rise in systemic corticosterone levels, indicating that GR is activated in microglia during the degeneration of dopamine neurons [129]. The unequivocal evidence that GR in microglia normally protects dopamine neurons was provided by experiments with mice in which the GR gene was selectively deleted in microglia/macrophages. MPTP treatment in these mice resulted in increased dopamine neuronal loss as well as increased microglial activation and expression of proinflammatory mediators [129]. Indeed, the absence of GR in microglia resulted in sustained activation of NF- $\kappa \mathrm{B}$ as was shown in these microglial GR mutants. The above findings have a significant relevance for PD pathogenesis as nuclear expression of p65 subunit of NF- $\kappa \mathrm{B}$, indicative of transcriptional activity, was found in the substantia nigra microglia of PD postmortem [160].

Inflammatory reaction mediated by immune-competent cells such as microglia is normally a very tightly regulated process of limited duration. It is very likely that the processes involved in the regulation of glial immune responses including the expression and secretion of inflammatory mediators are compromised in $\mathrm{PD}$ and also $\mathrm{AD}$ resulting in a chronic inflammatory state with sustained activation of glia spanning many years. One likely factor contributing to dysfunction of glial immune responses is aging. Immune-regulatory processes are compromised in aging (immunosenescence) and also during chronic stress [161] where there is an increased susceptibility to infections as well as proinflammatory cytokine production [162]. In aging, microglia show enhanced sensitivity to inflammatory stimuli, a process called "priming" which could be also induced by chronic stress and a dysregulated HPA axis. In this regard, there are several studies showing that chronically elevated GCs levels in response to different stressors cause proinflammatory cytokine production and sensitization or "priming" of microglia. Importantly, subsequent inflammatory or toxic stimuli result in aggravation of neuronal injury $[119,120,163]$. Moreover high and sustained GCs can exacerbate inflammation because of GC resistance whereby GR activity is affected. Thus it is plausible that GR transcriptional activity regulating inflammatory response of microglia is compromised in AD and PD patients who display persistently high GC levels.

7.2. GR, Inflammation and Nonmotor PD Symptoms. Recent experimental evidence shows that glia and peripheral immune cells are activated upon chronic psychogenic stress and that their actions are important in mood and behavior [164-167]. Glial production of potent proinflammatory cytokines such as TNF- $\alpha$, IL-6, and INF- $\gamma$ are implicated in depression through stimulation of the kynurenine pathway (shift of serotonin synthesis from tryptophan to kyneurin) in activated astroglia, microglia, and infiltrating peripheral immune cells. Kynurenine, produced from tryptophan by activation of indoleamine 2,3-dioxygenase (IDO), can be further converted to kynurenic acid or quinolinic acid, the latter affecting the function of both monoaminergic and glutamatergic neurons. Quinolinic acid toxicity with increased glutamate release results in lipid peroxidation and nitrative stress $[168,169]$ Evidence shows that the kynurenic acid/tryptophan ratio is altered in CSF and serum in PD patients [170].

Another means by which glial activation and proinflammatory cytokines promote mood anomalies in $\mathrm{PD}$ is through reducing neurogenesis in hippocampal subgranular zone, thus affecting hippocampus-mediated regulation of mood and cognition [171].

\section{Conclusion}

Clinical and preclinical studies suggest that chronic stress/ elevated GC levels may be an etiological factor in the development and progression of both $\mathrm{AD}$ and $\mathrm{PD}$ pathologies. Growing evidence indicates that the pathological manifestations of chronic stress include neuronal and synaptic atrophy/malfunction as well as immunosuppression, but our understanding of the underpinning mechanisms is still poor and calls for more research not only to identify therapeutic inroads but, also, preventative measures or ways to delay onset of disease.

\section{Conflict of Interests}

The authors declare that there is no conflict of interests regarding the publication of this paper.

\section{Acknowledgments}

The work was supported by Grants "PTDC/SAU-NMC/ 113934/2009," funded by FCT, Portuguese Foundation for Science and Technology, and project DoIT, Desenvolvimento e Operacionalização da Investigação de Translação 
( $\mathrm{N}^{\circ}$ do projeto 13853), funded by Fundo Europeu de Desenvolvimento Regional (FEDER) through the Programa Operacional Fatores de Competitividade (POFC). In addition, this work was also cofinanced by European Union FP7 Project SwitchBox (Nuno Sousa, Osborne F. X. Almeida) and the Portuguese North Regional Operational Program (ON.2 - O Novo Norte) under the National Strategic Reference Framework (QREN), through the European Regional Development Fund (FEDER). Sheela Vyas acknowledges grant support from Foundation de France, Physiopathology of Parkinson, France Parkinson and ANR Grant "ParkStrim" N ${ }^{\circ}$ 13-BSV10013-02. Work in FT research group was supported by Agence Nationale de la Recherche (TIMMS and StressPsyco) and Fondation pour la Recherche Médicale, Grant no. DEQ20140329552.

\section{References}

[1] B. S. McEwen, "Physiology and neurobiology of stress and adaptation: central role of the brain," Physiological Reviews, vol. 87, no. 3, pp. 873-904, 2007.

[2] M. Kivimäki and I. Kawachi, "Work stress as a risk factor for cardiovascular disease," Current Cardiology Reports, vol. 17, no. 9, article 630, 2015.

[3] B. S. McEwen, J. D. Gray, and C. Nasca, "60 YEARS OF NEUROENDOCRINOLOGY: redefining neuroendocrinology: stress, sex and cognitive and emotional regulation," Journal of Endocrinology, vol. 226, no. 2, pp. T67-T83, 2015.

[4] B. S. McEwen, N. P. Bowles, J. D. Gray et al., "Mechanisms of stress in the brain," Nature Neuroscience, vol. 18, no. 10, pp. 13531363, 2015.

[5] Y. Chen and T. Z. Baram, "Toward understanding how earlylife stress reprograms cognitive and emotional brain networks," Neuropsychopharmacology, vol. 41, no. 1, pp. 197-206, 2016.

[6] B. S. McEwen and J. H. Morrison, "The brain on stress: vulnerability and plasticity of the prefrontal cortex over the life course," Neuron, vol. 79, no. 1, pp. 16-29, 2013.

[7] I. Sotiropoulos, J. J. Cerqueira, C. Catania, A. Takashima, N. Sousa, and O. F. X. Almeida, "Stress and glucocorticoid footprints in the brain-the path from depression to Alzheimer's disease," Neuroscience and Biobehavioral Reviews, vol. 32, no. 6 , pp. 1161-1173, 2008.

[8] T. L. Bale and C. N. Epperson, "Sex differences and stress across the lifespan," Nature Neuroscience, vol. 18, no. 10, pp. 1413-1420, 2015.

[9] N. Sousa, "The dynamics of the stress neuromatrix," Molecular Psychiatry, 2016.

[10] J. A. Whitsett and Y. Matsuzaki, "Transcriptional regulation of perinatal lung maturation," Pediatric Clinics of North America, vol. 53, no. 5, pp. 873-887, 2006.

[11] K. M. Moritz, M. Dodic, and E. M. Wintour, "Kidney development and the fetal programming of adult disease," BioEssays, vol. 25 , no. 3 , pp. $212-220,2003$.

[12] A. Kapoor, E. Dunn, A. Kostaki, M. H. Andrews, and S. G. Matthews, "Fetal programming of hypothalamo-pituitaryadrenal function: prenatal stress and glucocorticoids," Journal of Physiology, vol. 572, part 1, pp. 31-44, 2006.

[13] H. D. Veldhuis, C. Van Koppen, M. Van Ittersum, and E. R. De Kloet, "Specificity of the adrenal steroid receptor system in rat hippocampus," Endocrinology, vol. 110, no. 6, pp. 2044-2051, 1982.
[14] B. S. McEwen, E. R. De Kloet, and W. Rostene, "Adrenal steroid receptors and actions in the nervous system," Physiological Reviews, vol. 66, no. 4, pp. 1121-1188, 1986.

[15] R. Ahima, Z. Krozowski, and R. Harlan, "Type I corticosteroid receptor-like immunoreactivity in the rat CNS: distribution and regulation by corticosteroids," Journal of Comparative Neurology, vol. 313, no. 3, pp. 522-538, 1991.

[16] J. M. H. M. Reul and E. R. de Kloet, “Two receptor systems for corticosterone in rat brain: microdistribution and differential occupation," Endocrinology, vol. 117, no. 6, pp. 2505-2511, 1985.

[17] E. R. De Kloet, E. Vreugdenhil, M. S. Oitzl, and M. Joëls, "Brain corticosteroid receptor balance in health and disease," Endocrine Reviews, vol. 19, no. 3, pp. 269-301, 1998.

[18] D. Obradović, M. Tirard, Z. Némethy, O. Hirsch, H. Gronemeyer, and O. F. X. Almeida, "DAXX, FLASH, and FAF1 modulate mineralocorticoid and glucocorticoid receptormediated transcription in hippocampal cells-toward a basis for the opposite actions elicited by two nuclear receptors?" Molecular Pharmacology, vol. 65, no. 3, pp. 761-769, 2004.

[19] M. Tirard, J. Jasbinsek, O. F. X. Almeida, and T. M. Michaelidis, "The manifold actions of the protein inhibitor of activated STAT proteins on the transcriptional activity of mineralocorticoid and glucocorticoid receptors in neural cells," Journal of Molecular Endocrinology, vol. 32, no. 3, pp. 825-841, 2004.

[20] V. G. Moisiadis and S. G. Matthews, "Glucocorticoids and fetal programming part 1: outcomes," Nature Reviews Endocrinology, vol. 10, no. 7, pp. 391-402, 2014.

[21] A. Harris and J. Seckl, "Glucocorticoids, prenatal stress and the programming of disease," Hormones and Behavior, vol. 59, no. 3, pp. 279-289, 2011.

[22] N. Sousa and O. F. X. Almeida, "Disconnection and reconnection: the morphological basis of (mal)adaptation to stress," Trends in Neurosciences, vol. 35, no. 12, pp. 742-751, 2012.

[23] S. Yang, F. Roselli, A. V. Patchev, S. Yu, and O. F. X. Almeida, "Non-receptor-tyrosine kinases integrate fast glucocorticoid signaling in hippocampal neurons," Journal of Biological Chemistry, vol. 288, no. 33, pp. 23725-23739, 2013.

[24] D. A. Stavreva, M. Wiench, S. John et al., "Ultradian hormone stimulation induces glucocorticoid receptor-mediated pulses of gene transcription," Nature Cell Biology, vol. 11, no. 9, pp. 1093$1102,2009$.

[25] G. M. Russell, K. Kalafatakis, and S. L. Lightman, "The importance of biological oscillators for hypothalamic-pituitaryadrenal activity and tissue glucocorticoid response: coordinating stress and neurobehavioural adaptation," Journal of Neuroendocrinology, vol. 27, no. 6, pp. 378-388, 2015.

[26] D. Ratman, W. Vanden Berghe, L. Dejager et al., "How glucocorticoid receptors modulate the activity of other transcription factors: a scope beyond tethering," Molecular and Cellular Endocrinology, vol. 380, no. 1-2, pp. 41-54, 2013.

[27] R. H. Oakley and J. A. Cidlowski, "The biology of the glucocorticoid receptor: new signaling mechanisms in health and disease," Journal of Allergy and Clinical Immunology, vol. 132, no. 5, pp. 1033-1044, 2013.

[28] O. J. L. M. Schoneveld, I. C. Gaemers, and W. H. Lamers, "Mechanisms of glucocorticoid signalling," Biochimica et Biophysica Acta, vol. 1680, no. 2, pp. 114-128, 2004.

[29] N. A. Datson, M. C. Morsink, O. C. Meijer, and E. R. de Kloet, "Central corticosteroid actions: search for gene targets," European Journal of Pharmacology, vol. 583, no. 2-3, pp. 272289, 2008. 
[30] J. R. Seckl, "Prenatal glucocorticoids and long-term programming," European Journal of Endocrinology, vol. 151, supplement 3, pp. U49-U62, 2004.

[31] V. G. Moisiadis and S. G. Matthews, "Glucocorticoids and fetal programming part 2: mechanisms," Nature Reviews Endocrinology, vol. 10, no. 7, pp. 403-411, 2014.

[32] C. Caldji, J. Diorio, and M. J. Meaney, "Variations in maternal care in infancy regulate the development of stress reactivity," Biological Psychiatry, vol. 48, no. 12, pp. 1164-1174, 2000.

[33] I. C. G. Weaver, N. Cervoni, F. A. Champagne et al., "Epigenetic programming by maternal behavior," Nature Neuroscience, vol. 7, no. 8, pp. 847-854, 2004.

[34] P. O. McGowan, A. Sasaki, A. C. D’Alessio et al., "Epigenetic regulation of the glucocorticoid receptor in human brain associates with childhood abuse," Nature Neuroscience, vol. 12, no. 3, pp. 342-348, 2009.

[35] T. F. Oberlander, J. Weinberg, M. Papsdorf, R. Grunau, S. Misri, and A. M. Devlin, "Prenatal exposure to maternal depression, neonatal methylation of human glucocorticoid receptor gene (NR3C1) and infant cortisol stress responses," Epigenetics, vol. 3, no. 2, pp. 97-106, 2008.

[36] A. J. Rodrigues, P. Leão, J. M. Pêgo et al., "Mechanisms of initiation and reversal of drug-seeking behavior induced by prenatal exposure to glucocorticoids," Molecular Psychiatry, vol. 17, no. 12, pp. 1295-1305, 2012.

[37] Y. Bockmühl, A. V. Patchev, A. Madejska et al., "Methylation at the CpG Island Shore Region Uupregulates Nr3c1 Promoter Activity after Early-Life Stress," Epigenetics, vol. 10, no. 3, pp. 247-257, 2015.

[38] C. Murgatroyd, A. V. Patchev, Y. Wu et al., "Dynamic DNA methylation programs persistent adverse effects of early-life stress," Nature Neuroscience, vol. 12, no. 12, pp. 1559-1566, 2009.

[39] A. R. Borenstein, C. I. Copenhaver, and J. A. Mortimer, "Earlylife risk factors for Alzheimer disease," Alzheimer Disease and Associated Disorders, vol. 20, no. 1, pp. 63-72, 2006.

[40] E. Martisova, B. Aisa, G. Guereñu, and M. J. Ramírez, "Effects of early maternal separation on biobehavioral and neuropathological markers of Alzheimer's disease in adult male rats," Current Alzheimer Research, vol. 10, no. 4, pp. 420-432, 2013.

[41] J. Gräff, D. Rei, J.-S. Guan et al., "An epigenetic blockade of cognitive functions in the neurodegenerating brain," Nature, vol. 483, no. 7388, pp. 222-226, 2012.

[42] G. Faa, M. Marcialis, A. Ravarino, M. Piras, M. Pintus, and V. Fanos, "Fetal programming of the human brain: is there a link with insurgence of neurodegenerative disorders in adulthood?" Current Medicinal Chemistry, vol. 21, no. 33, pp. 3854-3876, 2014.

[43] J. G. Goldman and R. Postuma, "Premotor and nonmotor features of Parkinson's disease," Current Opinion in Neurology, vol. 27, no. 4, pp. 434-441, 2014.

[44] I. S. Pienaar, L. A. Kellaway, V. A. Russell et al., "Maternal separation exaggerates the toxic effects of 6-hydroxydopamine in rats: implications for neurodegenerative disorders," Stress, vol. 11, no. 6, pp. 448-456, 2008.

[45] P. M. Carvey, Q. Chang, J. W. Lipton, and Z. Ling, "Prenatal exposure to the bacteriotoxin lipopolysaccharide leads to longterm losses of dopamine neurons in offspring: a potential, new model of Parkinson's disease," Frontiers in Bioscience, vol. 8, pp. s826-s837, 2003.

[46] C. J. Baier, M. R. Katunar, E. Adrover, M. E. Pallares, and M. C. Antonelli, "Gestational restraint stress and the developing dopaminergic system: an overview," Neurotoxicity Research, vol. 22, no. 1, pp. 16-32, 2012.

[47] M. Simard, C. Hudon, and R. van Reekum, "Psychological distress and risk for dementia," Current Psychiatry Reports, vol. 11, no. 1, pp. 41-47, 2009.

[48] S. Mejía, M. Giraldo, D. Pineda, A. Ardila, and F. Lopera, "Nongenetic factors as modifiers of the age of onset of familial Alzheimer's disease," International Psychogeriatrics, vol. 15, no. 4, pp. 337-349, 2003.

[49] B. S. Greenwald, A. A. Mathe, R. C. Mohs, M. I. Levy, C. A. Johns, and K. L. Davis, "Cortisol and Alzheimer's disease, II: dexamethasone suppression, dementia severity, and affective symptoms," American Journal of Psychiatry, vol. 143, no. 4, pp. 442-446, 1986.

[50] M. Hatzinger, A. Z’Brun, U. Hemmeter et al., "Hypothalamicpituitary-adrenal system function in patients with Alzheimer's disease," Neurobiology of Aging, vol. 16, no. 2, pp. 205-209, 1995.

[51] S. Rasmuson, R. Andrew, B. Näsman, J. R. Seckl, B. R. Walker, and T. Olsson, "Increased glucocorticoid production and altered cortisol metabolism in women with mild to moderate Alzheimer's disease," Biological Psychiatry, vol. 49, no. 6, pp. 547-552, 2001.

[52] E. R. Peskind, C. W. Wilkinson, E. C. Petrie, G. D. Schellenberg, and M. A. Raskind, "Increased CSF cortisol in AD is a function of APOE genotype," Neurology, vol. 56, no. 8, pp. 1094-1098, 2001.

[53] W. J. G. Hoogendijk, G. Meynen, E. Endert, M. A. Hofman, and D. F. Swaab, "Increased cerebrospinal fluid cortisol level in Alzheimer's disease is not related to depression," Neurobiology of Aging, vol. 27, no. 5, pp. 780.el-780.e2, 2006.

[54] A. Hartmann, J. D. Veldhuis, M. Deuschle, H. Standhardt, and I. Heuser, "Twenty-four hour cortisol release profiles in patients with Alzheimer's and Parkinson's disease compared to normal controls: ultradian secretory pulsatility and diurnal variation," Neurobiology of Aging, vol. 18, no. 3, pp. 285-289, 1997.

[55] S. M. Rothman and M. P. Mattson, "Adverse stress, hippocampal networks, and Alzheimer's disease," NeuroMolecular Medicine, vol. 12, no. 1, pp. 56-70, 2010.

[56] J. G. Csernansky, H. Dong, A. M. Fagan et al., "Plasma cortisol and progression of dementia in subjects with Alzheimer-type dementia," The American Journal of Psychiatry, vol. 163, no. 12, pp. 2164-2169, 2006.

[57] E. Elgh, A. Lindqvist Åstot, M. Fagerlund, S. Eriksson, T. Olsson, and B. Näsman, "Cognitive dysfunction, hippocampal atrophy and glucocorticoid feedback in Alzheimer's disease," Biological Psychiatry, vol. 59, no. 2, pp. 155-161, 2006.

[58] P. J. Lucassen, J. Pruessner, N. Sousa et al., "Neuropathology of stress," Acta Neuropathologica, vol. 127, no. 1, pp. 109-135, 2014.

[59] M. Egeland, P. A. Zunszain, and C. M. Pariante, "Molecular mechanisms in the regulation of adult neurogenesis during stress," Nature Reviews Neuroscience, vol. 16, no. 4, pp. 189-200, 2015.

[60] E. Gould, P. Tanapat, B. S. Mcewen, G. Flügge, and E. Fuchs, "Proliferation of granule cell precursors in the dentate gyrus of adult monkeys is diminished by stress," Proceedings of the National Academy of Sciences of the United States of America, vol. 95, no. 6, pp. 3168-3171, 1998.

[61] J. M. Bessa, D. Ferreira, I. Melo et al., "The mood-improving actions of antidepressants do not depend on neurogenesis but are associated with neuronal remodeling," Molecular Psychiatry, vol. 14, no. 8, pp. 764-773, 2009. 
[62] M. Morais, P. A. R. Santos, A. Mateus-Pinheiro et al., "The effects of chronic stress on hippocampal adult neurogenesis and dendritic plasticity are reversed by selective MAO-A inhibition," Journal of Psychopharmacology, vol. 28, no. 12, pp. 1178-1183, 2014.

[63] E. Y. H. Wong and J. Herbert, "Raised circulating corticosterone inhibits neuronal differentiation of progenitor cells in the adult hippocampus," Neuroscience, vol. 137, no. 1, pp. 83-92, 2006.

[64] C. A. Oomen, J. L. Mayer, E. R. De Kloet, M. Joëls, and P. J. Lucassen, "Brief treatment with the glucocorticoid receptor antagonist mifepristone normalizes the reduction in neurogenesis after chronic stress," European Journal of Neuroscience, vol. 26, no. 12, pp. 3395-3401, 2007.

[65] R. J. Schloesser, H. K. Manji, and K. Martinowich, "Suppression of adult neurogenesis leads to an increased hypothalamopituitary-adrenal axis response," NeuroReport, vol. 20, no. 6, pp. 553-557, 2009.

[66] J. S. Snyder, A. Soumier, M. Brewer, J. Pickel, and H. A. Cameron, "Adult hippocampal neurogenesis buffers stress responses and depressive behaviour," Nature, vol. 476, no. 7361, pp. 458-462, 2011.

[67] J. J. Rodríguez and A. Verkhratsky, "Neurogenesis in Alzheimer's disease," Journal of Anatomy, vol. 219, no. 1, pp. 78-89, 2011.

[68] J. J. Cerqueira, F. Mailliet, O. F. X. Almeida, T. M. Jay, and N. Sousa, "The prefrontal cortex as a key target of the maladaptive response to stress," Journal of Neuroscience, vol. 27, no. 11, pp. 2781-2787, 2007.

[69] C. Duyckaerts, B. Delatour, and M.-C. Potier, "Classification and basic pathology of Alzheimer disease," Acta Neuropathologica, vol. 118, no. 1, pp. 5-36, 2009.

[70] E. Karran, M. Mercken, and B. D. Strooper, "The amyloid cascade hypothesis for Alzheimer's disease: an appraisal for the development of therapeutics," Nature Reviews Drug Discovery, vol. 10, no. 9, pp. 698-712, 2011.

[71] C. Ballard, S. Gauthier, A. Corbett, C. Brayne, D. Aarsland, and E. Jones, “Alzheimer's disease," The Lancet, vol. 377, no. 9770, pp. 1019-1031, 2011.

[72] F. Roselli, M. Tirard, J. Lu et al., "Soluble $\beta$-amyloid1-40 induces NMDA-dependent degradation of postsynaptic density-95 at glutamatergic synapses," Journal of Neuroscience, vol. 25, no. 48, pp. 11061-11070, 2005.

[73] S. Tu, S. Okamoto, S. A. Lipton, and H. Xu, "Oligomeric A $\beta$ induced synaptic dysfunction in Alzheimer's disease," Molecular Neurodegeneration, vol. 9, no. 1, article 48, 2014.

[74] M. Rapoport, H. N. Dawson, L. I. Binder, M. P. Vitek, and A. Ferreira, "Tau is essential to $\beta$-amyloid-induced neurotoxicity," Proceedings of the National Academy of Sciences of the United States of America, vol. 99, no. 9, pp. 6364-6369, 2002.

[75] E. D. Roberson, K. Scearce-Levie, J. J. Palop et al., "Reducing endogenous tau ameliorates amyloid $\beta$-induced deficits in an Alzheimer's disease mouse model," Science, vol. 316, no. 5825, pp. 750-754, 2007.

[76] K. A. Vossel, K. Zhang, J. Brodbeck et al., "Tau reduction prevents $A \beta$-induced defects in axonal transport," Science, vol. 330, no. 6001, p. 198, 2010.

[77] K. A. Vossel, J. C. Xu, V. Fomenko et al., “Tau reduction prevents $\mathrm{A} \beta$-induced axonal transport deficits by blocking activation of GSK3 $\beta$," The Journal of Cell Biology, vol. 209, no. 3, pp. 419-433, 2015.
[78] T. Gómez-Isla, R. Hollister, H. West et al., "Neuronal loss correlates with but exceeds neurofibrillary tangles in Alzheimer's disease," Annals of Neurology, vol. 41, no. 1, pp. 17-24, 1997.

[79] L. C. de Souza, M. Chupin, F. Lamari et al., "CSF tau markers are correlated with hippocampal volume in Alzheimer's disease," Neurobiology of Aging, vol. 33, no. 7, pp. 1253-1257, 2012.

[80] K. N. Green, L. M. Billings, B. Roozendaal, J. L. McGaugh, and F. M. LaFerla, "Glucocorticoids increase amyloid- $\beta$ and tau pathology in a mouse model of Alzheimer's disease," Journal of Neuroscience, vol. 26, no. 35, pp. 9047-9056, 2006.

[81] Y. H. Jeong, C. H. Park, J. Yoo et al., "Chronic stress accelerates learning and memory impairments and increases amyloid deposition in $\mathrm{APP}_{\mathrm{V} 717 \mathrm{I}}$-CT100 transgenic mice, an Alzheimer's disease model," The FASEB Journal, vol. 20, no. 6, pp. 729-731, 2006.

[82] I. Sotiropoulos, C. Catania, T. Riedemann et al., "Glucocorticoids trigger Alzheimer disease-like pathobiochemistry in rat neuronal cells expressing human tau," Journal of Neurochemistry, vol. 107, no. 2, pp. 385-397, 2008.

[83] C. Catania, I. Sotiropoulos, R. Silva et al., "The amyloidogenic potential and behavioral correlates of stress," Molecular Psychiatry, vol. 14, no. 1, pp. 95-105, 2009.

[84] B. A. Stein-Behrens, E. M. Elliott, C. A. Miller, J. W. Schilling, R. Newcombe, and R. M. Sapolsky, "Glucocorticoids exacerbate kainic acid-induced extracellular accumulation of excitatory amino acids in the rat hippocampus," Journal of Neurochemistry, vol. 58, no. 5, pp. 1730-1735, 1992.

[85] I. Sotiropoulos, C. Catania, L. G. Pinto et al., "Stress acts cumulatively to precipitate Alzheimer's disease-like tau pathology and cognitive deficits," Journal of Neuroscience, vol. 31, no. 21, pp. 7840-7847, 2011.

[86] L. M. Callahan, W. A. Vaules, and P. D. Coleman, "Progressive reduction of synaptophysin message in single neurons in Alzheimer disease," Journal of Neuropathology and Experimental Neurology, vol. 61, no. 5, pp. 384-395, 2002.

[87] J. Lauckner, P. Frey, and C. Geula, "Comparative distribution of tau phosphorylated at Ser262 in pre-tangles and tangles," Neurobiology of Aging, vol. 24, no. 6, pp. 767-776, 2003.

[88] H. Hampel, K. Bürger, J. C. Pruessner et al., "Correlation of cerebrospinal fluid levels of tau protein phosphorylated at threonine 231 with rates of hippocampal atrophy in Alzheimer disease," Archives of Neurology, vol. 62, no. 5, pp. 770-773, 2005.

[89] J. C. Augustinack, A. Schneider, E.-M. Mandelkow, and B. T. Hyman, "Specific tau phosphorylation sites correlate with severity of neuronal cytopathology in Alzheimer's disease," Acta Neuropathologica, vol. 103, no. 1, pp. 26-35, 2002.

[90] M. Ewers, K. Buerger, S. J. Teipel et al., "Multicenter assessment of CSF-phosphorylated tau for the prediction of conversion of MCI," Neurology, vol. 69, no. 24, pp. 2205-2212, 2007.

[91] A. E. van der Vlies, N. A. Verwey, F. H. Bouwman et al., "CSF biomarkers in relationship to cognitive profiles in Alzheimer disease," Neurology, vol. 72, no. 12, pp. 1056-1061, 2009.

[92] J. C. Carroll, M. Iba, D. A. Bangasser et al., "Chronic stress exacerbates tau pathology, neurodegeneration, and cognitive performance through a corticotropin-releasing factor receptordependent mechanism in a transgenic mouse model of tauopathy," Journal of Neuroscience, vol. 31, no. 40, pp. 14436-14449, 2011.

[93] R. A. Rissman, K.-F. Lee, W. Vale, and P. E. Sawchenko, "Corticotropin-releasing factor receptors differentially regulate stress-induced tau phosphorylation," Journal of Neuroscience, vol. 27, no. 24, pp. 6552-6562, 2007. 
[94] I. Sotiropoulos, J. Silva, T. Kimura et al., "Female hippocampus vulnerability to environmental stress, a precipitating factor in Tau aggregation pathology," Journal of Alzheimer's Disease, vol. 43, no. 3, pp. 763-774, 2015.

[95] A. de Calignon, M. Polydoro, M. Suárez-Calvet et al., "Propagation of tau pathology in a model of early Alzheimer's disease," Neuron, vol. 73, no. 4, pp. 685-697, 2012.

[96] Y. P. Wang, J. Biernat, M. Pickhardt, E. Mandelkow, and E.-M. Mandelkow, "Stepwise proteolysis liberates tau fragments that nucleate the Alzheimer-like aggregation of full-length tau in a neuronal cell model," Proceedings of the National Academy of Sciences of the United States of America, vol. 104, no. 24, pp. 10252-10257, 2007.

[97] R. A. Rissman, W. W. Poon, M. Blurton-Jones et al., "Caspasecleavage of tau is an early event in Alzheimer disease tangle pathology," Journal of Clinical Investigation, vol. 114, no. 1, pp. 121-130, 2004.

[98] C. L. Weaver, M. Espinoza, Y. Kress, and P. Davies, “Conformational change as one of the earliest alterations of tau in Alzheimer's disease," Neurobiology of Aging, vol. 21, no. 5, pp. 719-727, 2000.

[99] E. R. de Kloet, M. Joëls, and F. Holsboer, "Stress and the brain: from adaptation to disease," Nature Reviews Neuroscience, vol. 6, no. 6, pp. 463-475, 2005.

[100] M. A. Rapp, M. Schnaider-Beeri, H. T. Grossman et al., "Increased hippocampal plaques and tangles in patients with Alzheimer disease with a lifetime history of major depression," Archives of General Psychiatry, vol. 63, no. 2, pp. 161-167, 2006.

[101] R. Mayeux, L. S. Honig, M.-X. Tang et al., "Plasma A $\beta 40$ and $\mathrm{A} \beta 42$ and Alzheimer's disease: relation to age, mortality, and risk," Neurology, vol. 61, no. 9, pp. 1185-1190, 2003.

[102] N. Andreasen and K. Blennow, "CSF biomarkers for mild cognitive impairment and early Alzheimer's disease," Clinical Neurology and Neurosurgery, vol. 107, no. 3, pp. 165-173, 2005.

[103] A. Post, N. Ackl, M. Rücker et al., "Toward a reliable distinction between patients with mild cognitive impairment and Alzheimer-type dementia versus major depression," Biological Psychiatry, vol. 59, no. 9, pp. 858-862, 2006.

[104] X. Sun, D. C. Steffens, R. Au et al., "Amyloid-associated depression: a prodromal depression of Alzheimer disease?" Archives of General Psychiatry, vol. 65, no. 5, pp. 542-550, 2008.

[105] Y. I. Sheline, T. West, K. Yarasheski et al., "An antidepressant decreases CSF $\mathrm{A} \beta$ production in healthy individuals and in transgenic AD mice," Science Translational Medicine, vol. 6, no. 236, Article ID 236re4, 2014.

[106] S. U. Qureshi, T. Kimbrell, J. M. Pyne et al., "Greater prevalence and incidence of dementia in older veterans with posttraumatic stress disorder," Journal of the American Geriatrics Society, vol. 58, no. 9, pp. 1627-1633, 2010.

[107] S. Prokop, K. R. Miller, and F. L. Heppner, "Microglia actions in Alzheimer's disease," Acta Neuropathologica, vol. 126, no. 4, pp. 461-477, 2013.

[108] E. G. McGeer and P. L. McGeer, "The importance of inflammatory mechanisms in Alzheimer disease," Experimental Gerontology, vol. 33, no. 5, pp. 371-378, 1998.

[109] B. Olsson, J. Hertze, R. Lautner et al., "Microglial markers are elevated in the prodromal phase of Alzheimer's disease and vascular dementia," Journal of Alzheimer's Disease, vol. 33, no. 1, pp. 45-53, 2013.

[110] D. M. Paresce, R. N. Ghosh, and F. R. Maxfield, "Microglial cells internalize aggregates of the Alzheimer's disease amyloid $\beta$-protein via a scavenger receptor," Neuron, vol. 17, no. 3, pp. $553-565,1996$.

[111] J. Koenigsknecht and G. Landreth, "Microglial phagocytosis of fibrillar $\beta$-amyloid through a $\beta 1$ integrin-dependent mechanism," Journal of Neuroscience, vol. 24, no. 44, pp. 9838-9846, 2004.

[112] P. A. Zunszain, N. Hepgul, and C. M. Pariante, "Inflammation and depression," Current Topics in Behavioral Neurosciences, vol. 14, pp. 135-151, 2013.

[113] S. D. Mhatre, C. A. Tsai, A. J. Rubin, M. L. James, and K. I. Andreasson, "Microglial malfunction: the third rail in the development of Alzheimer's disease," Trends in Neurosciences, vol. 38, no. 10, pp. 621-636, 2015.

[114] Y. Zhu, E. Nwabuisi-Heath, S. B. Dumanis et al., "APOE genotype alters glial activation and loss of synaptic markers in mice," Glia, vol. 60, no. 4, pp. 559-569, 2012.

[115] Y. Wang, M. Cella, K. Mallinson et al., “TREM2 lipid sensing sustains the microglial response in an Alzheimer's disease model," Cell, vol. 160, no. 6, pp. 1061-1071, 2015.

[116] G. Krabbe, A. Halle, V. Matyash et al., "Functional impairment of microglia coincides with $\beta$-amyloid deposition in mice with Alzheimer-like pathology," PLoS ONE, vol. 8, no. 4, Article ID e60921, 2013.

[117] S. E. Hickman, E. K. Allison, and J. El Khoury, "Microglial dysfunction and defective $\beta$-amyloid clearance pathways in aging Alzheimer's disease mice," Journal of Neuroscience, vol. 28, no. 33, pp. 8354-8360, 2008.

[118] W. J. Streit, H. Braak, Q.-S. Xue, and I. Bechmann, "Dystrophic (senescent) rather than activated microglial cells are associated with tau pathology and likely precede neurodegeneration in Alzheimer's disease," Acta Neuropathologica, vol. 118, no. 4, pp. 475-485, 2009.

[119] R. M. de Pablos, R. F. Villarán, S. Argüelles et al., "Stress increases vulnerability to inflammation in the rat prefrontal cortex," The Journal of Neuroscience, vol. 26, no. 21, pp. 57095719, 2006.

[120] C. D. Munhoz, S. F. Sorrells, J. R. Caso, C. Scavone, and R. M. Sapolsky, "Glucocorticoids exacerbate lipopolysaccharideinduced signaling in the frontal cortex and hippocampus in a dose-dependent manner," Journal of Neuroscience, vol. 30, no. 41, pp. 13690-13698, 2010.

[121] H. Braak, K. del Tredici, U. Rüb, R. A. I. de Vos, E. N. H. Jansen Steur, and E. Braak, "Staging of brain pathology related to sporadic Parkinson's disease," Neurobiology of Aging, vol. 24, no. 2, pp. 197-211, 2003.

[122] K. Wakabayashi and H. Takahashi, "Neuropathology of autonomic nervous system in Parkinson's disease," European Neurology, vol. 38, supplement 2, pp. 2-7, 1997.

[123] H. Braak, C. M. Müller, U. Rüb et al., "Pathology associated with sporadic Parkinson's disease-where does it end?" in Parkinson's Disease and Related Disorders, vol. 70 of Journal of Neural Transmission. Supplementa, pp. 89-97, Springer, Berlin, Germany, 2006.

[124] P. A. Kempster, S. S. O’Sullivan, J. L. Holton, T. Revesz, and A. J. Lees, "Relationships between age and late progression of Parkinson's disease: a clinico-pathological study," Brain, vol. 133, part 6, pp. 1755-1762, 2010.

[125] O. Corti, S. Lesage, and A. Brice, "What genetics tells us about the causes and mechanisms of Parkinson's disease," Physiological Reviews, vol. 91, no. 4, pp. 1161-1218, 2011. 
[126] J. M. Rabey, M. Scharf, Z. Oberman, M. Zohar, and E. Graff, "Cortisol, ACTH, and beta-endorphin after dexamethasone administration in Parkinson's dementia," Biological Psychiatry, vol. 27, no. 6, pp. 581-591, 1990.

[127] G. Stypuła, J. Kunert-Radek, H. Stępień, K. Zylińska, and M. Pawlikowski, "Evaluation of interleukins, ACTH, cortisol and prolactin concentrations in the blood of patients with Parkinson's disease," NeuroImmunoModulation, vol. 3, no. 2-3, pp. 131-134, 1996.

[128] A. Charlett, R. J. Dobbs, A. G. Purkiss et al., "Cortisol is higher in parkinsonism and associated with gait deficit," Acta Neurologica Scandinavica, vol. 97, no. 2, pp. 77-85, 1998.

[129] F. Ros-Bernal, S. Hunot, M. T. Herrero et al., "Microglial glucocorticoid receptors play a pivotal role in regulating dopaminergic neurodegeneration in parkinsonism," Proceedings of the National Academy of Sciences of the United States of America, vol. 108, no. 16, pp. 6632-6637, 2011.

[130] K. Zou, W. Guo, G. Tang, B. Zheng, and Z. Zheng, "A case of early onset Parkinson's disease after major stress," Neuropsychiatric Disease and Treatment, vol. 9, pp. 1067-1069, 2013.

[131] A. D. Smith, S. L. Castro, and M. J. Zigmond, "Stress-induced Parkinson's disease: a working hypothesis," Physiology and Behavior, vol. 77, no. 4-5, pp. 527-531, 2002.

[132] G. A. Metz, "Stress as a modulator of motor system function and pathology," Reviews in the Neurosciences, vol. 18, no. 3-4, pp. 209-222, 2007.

[133] A. M. Snyder, E. M. Stricker, and M. J. Zigmond, "Self-induced neurological impairments in an animal model of parkinsonism," Annals of Neurology, vol. 18, no. 5, pp. 544-551, 1985.

[134] A. M. Hemmerle, J. W. Dickerson, J. P. Herman, and K. B. Seroogy, "Stress exacerbates experimental Parkinson's disease," Molecular Psychiatry, vol. 19, no. 6, pp. 638-640, 2014.

[135] E. Dias-Ferreira, J. C. Sousa, I. Melo et al., "Chronic stress causes frontostriatal reorganization and affects decision-making," Science, vol. 325, no. 5940, pp. 621-625, 2009.

[136] J. Goodman, K. C. Leong, and M. G. Packard, “Glucocorticoid enhancement of dorsolateral striatum-dependent habit memory requires concurrent noradrenergic activity," Neuroscience, vol. 311, pp. 1-8, 2015.

[137] M. A. Menza, L. I. Golbe, R. A. Cody, and N. E. Forman, "Dopamine-related personality traits in Parkinson's disease," Neurology, vol. 43, no. 3, part 1, pp. 505-508, 1993.

[138] E. J. Nestler and W. A. Carlezon Jr., "The mesolimbic dopamine reward circuit in depression," Biological Psychiatry, vol. 59, no. 12, pp. 1151-1159, 2006.

[139] K. M. Tye, J. J. Mirzabekov, M. R. Warden et al., "Dopamine neurons modulate neural encoding and expression of depressionrelated behaviour," Nature, vol. 493, no. 7433, pp. 537-541, 2013.

[140] D. Chaudhury, J. J. Walsh, A. K. Friedman et al., "Rapid regulation of depression-related behaviours by control of midbrain dopamine neurons," Nature, vol. 493, no. 7433, pp. 532-536, 2013.

[141] J. Barik, F. Marti, C. Morel et al., "Chronic stress triggers social aversion via glucocorticoid receptor in dopaminoceptive neurons," Science, vol. 339, no. 6117, pp. 332-335, 2013.

[142] M. Matsumoto and M. Takada, "Distinct representations of cognitive and motivational signals in midbrain dopamine neurons," Neuron, vol. 79, no. 5, pp. 1011-1024, 2013.

[143] A. K. Friedman, J. J. Walsh, B. Juarez et al., "Enhancing depression mechanisms in midbrain dopamine neurons achieves homeostatic resilience," Science, vol. 344, no. 6181, pp. 313-319, 2014.
[144] N. G. Hollon, L. M. Burgeno, and P. E. Phillips, "Stress effects on the neural substrates of motivated behavior," Nature Neuroscience, vol. 18, no. 10, pp. 1405-1412, 2015.

[145] T. C. Francis, R. Chandra, D. M. Friend et al., "Nucleus accumbens medium spiny neuron subtypes mediate depressionrelated outcomes to social defeat stress," Biological Psychiatry, vol. 77, no. 3, pp. 212-222, 2015.

[146] B. K. Lim, K. W. Huang, B. A. Grueter, P. E. Rothwell, and R. C. Malenka, "Anhedonia requires MC4R-mediated synaptic adaptations in nucleus accumbens," Nature, vol. 487, no. 7406, pp. 183-189, 2012.

[147] Y. Ouchi, E. Yoshikawa, Y. Sekine et al., "Microglial activation and dopamine terminal loss in early Parkinson's disease," Annals of Neurology, vol. 57, no. 2, pp. 168-175, 2005.

[148] S. Iannaccone, C. Cerami, M. Alessio et al., "In vivo microglia activation in very early dementia with Lewy bodies, comparison with Parkinson's disease," Parkinsonism and Related Disorders, vol. 19, no. 1, pp. 47-52, 2013.

[149] E. C. Hirsch and S. Hunot, "Neuroinflammation in Parkinson's disease: a target for neuroprotection?" The Lancet Neurology, vol. 8, no. 4, pp. 382-397, 2009.

[150] S. Phani, J. D. Loike, and S. Przedborskia, "Neurodegeneration and inflammation in Parkinson's disease," Parkinsonism and Related Disorders, vol. 18, supplement 1, pp. S207-S209, 2012.

[151] L. Pihlstrøm, G. Axelsson, K. A. Bjørnarå et al., "Supportive evidence for 11 loci from genome-wide association studies in Parkinson's disease," Neurobiology of Aging, vol. 34, no. 6, pp. 1708.e7-1708.e13, 2013.

[152] N. Dzamko, C. Geczy, and G. Halliday, "Inflammation is genetically implicated in Parkinson's disease," Neuroscience, vol. 302, pp. 89-102, 2015.

[153] G. T. Liberatore, V. Jackson-Lewis, S. Vukosavic et al., "Inducible nitric oxide synthase stimulates dopaminergic neurodegeneration in the MPTP model of Parkinson disease," Nature Medicine, vol. 5, no. 12, pp. 1403-1409, 1999.

[154] S. Hunot, M. Vila, P. Teismann et al., "JNK-mediated induction of cyclooxygenase 2 is required for neurodegeneration in a mouse model of Parkinson's disease," Proceedings of the National Academy of Sciences of the United States of America, vol. 101, no. 2, pp. 665-670, 2004.

[155] T. Furuya, H. Hayakawa, M. Yamada et al., "Caspase-11 mediates inflammatory dopaminergic cell death in the 1-methyl-4phenyl-1,2,3,6-tetrahydropyridine mouse model of Parkinson's disease," Journal of Neuroscience, vol. 24, no. 8, pp. 1865-1872, 2004.

[156] M. P. Mount, A. Lira, D. Grimes et al., "Involvement of interferon-gamma in microglial-mediated loss of dopaminergic neurons," Journal of Neuroscience, vol. 27, no. 12, pp. 3328-3337, 2007.

[157] A. Castaño, A. J. Herrera, J. Cano, and A. Machado, "The degenerative effect of a single intranigral injection of LPS on the dopaminergic system is prevented by dexamethasone, and not mimicked by rh-TNF- $\alpha$ IL- $1 \beta$ IFN- $\gamma$," Journal of Neurochemistry, vol. 81, no. 1, pp. 150-157, 2002.

[158] I. Kurkowska-Jastrzebska, A. Wrońska, M. Kohutnicka, A. Czlonkowski, and A. Czlonkowska, "The inflammatory reaction following 1-methyl-4-phenyl-1,2,3,6- tetrahydropyridine intoxication in mouse," Experimental Neurology, vol. 156, no. 1, pp. 50-61, 1999. 
[159] S. Sugama, T. Takenouchi, H. Kitani, M. Fujita, and M. Hashimoto, "Microglial activation is inhibited by corticosterone in dopaminergic neurodegeneration," Journal of Neuroimmunology, vol. 208, no. 1-2, pp. 104-114, 2009.

[160] A. Ghosh, A. Roy, X. Liu et al., "Selective inhibition of NF$\kappa \mathrm{B}$ activation prevents dopaminergic neuronal loss in a mouse model of Parkinson's disease," Proceedings of the National Academy of Sciences of the United States of America, vol. 104, no. 47, pp. 18754-18759, 2007.

[161] M. E. Bauer, C. M. M. Jeckel, and C. Luz, "The role of stress factors during aging of the immune system," Annals of the New York Academy of Sciences, vol. 1153, pp. 139-152, 2009.

[162] A. Panda, A. Arjona, E. Sapey et al., "Human innate immunosenescence: causes and consequences for immunity in old age," Trends in Immunology, vol. 30, no. 7, pp. 325-333, 2009.

[163] M. G. Frank, B. M. Thompson, L. R. Watkins, and S. F. Maier, "Glucocorticoids mediate stress-induced priming of microglial pro-inflammatory responses," Brain, Behavior, and Immunity, vol. 26, no. 2, pp. 337-345, 2012.

[164] R. Dantzer, J. C. O'Connor, G. G. Freund, R. W. Johnson, and K. W. Kelley, "From inflammation to sickness and depression: when the immune system subjugates the brain," Nature Reviews Neuroscience, vol. 9, no. 1, pp. 46-56, 2008.

[165] R. J. Tynan, J. Weidenhofer, M. Hinwood, M. J. Cairns, T. A. Day, and F. R. Walker, "A comparative examination of the antiinflammatory effects of SSRI and SNRI antidepressants on LPS stimulated microglia," Brain, Behavior, and Immunity, vol. 26, no. 3, pp. 469-479, 2012.

[166] M. Banasr, G. M. I. Chowdhury, R. Terwilliger et al., "Glial pathology in an animal model of depression: reversal of stressinduced cellular, metabolic and behavioral deficits by the glutamate-modulating drug riluzole," Molecular Psychiatry, vol. 15, no. 5, pp. 501-511, 2010.

[167] E. S. Wohleb, M. L. Hanke, A. W. Corona et al., “ $\beta$-adrenergic receptor antagonism prevents anxiety-like behavior and microglial reactivity induced by repeated social defeat," The Journal of Neuroscience, vol. 31, no. 17, pp. 6277-6288, 2011.

[168] R. G. Tavares, C. I. Tasca, C. E. S. Santos et al., "Quinolinic acid stimulates synaptosomal glutamate release and inhibits glutamate uptake into astrocytes," Neurochemistry International, vol. 40, no. 7, pp. 621-627, 2002.

[169] G. J. Guillemin, "Quinolinic acid: neurotoxicity," FEBS Journal, vol. 279, no. 8, p. 1355, 2012.

[170] B. Widner, F. Leblhuber, and D. Fuchs, "Increased neopterin production and tryptophan degradation in advanced Parkinson's disease," Journal of Neural Transmission, vol. 109, no. 2, pp. 181-189, 2002.

[171] P. J. Lucassen, C. A. Oomen, E. F. Naninck et al., "Regulation of adult neurogenesis and plasticity by (early) stress, glucocorticoids, and inflammation," Cold Spring Harbor Perspectives in Biology, vol. 7, no. 9, 2015. 

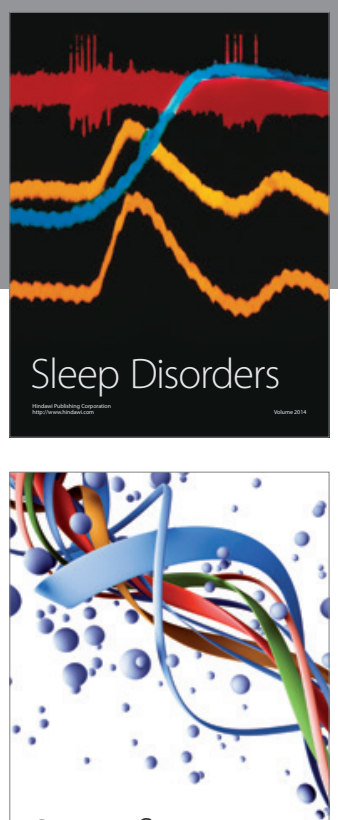

Scientifica
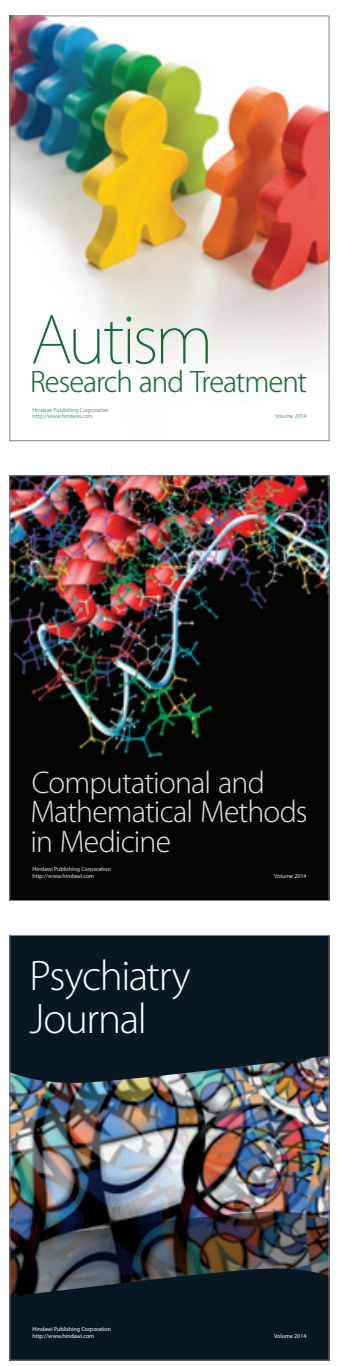
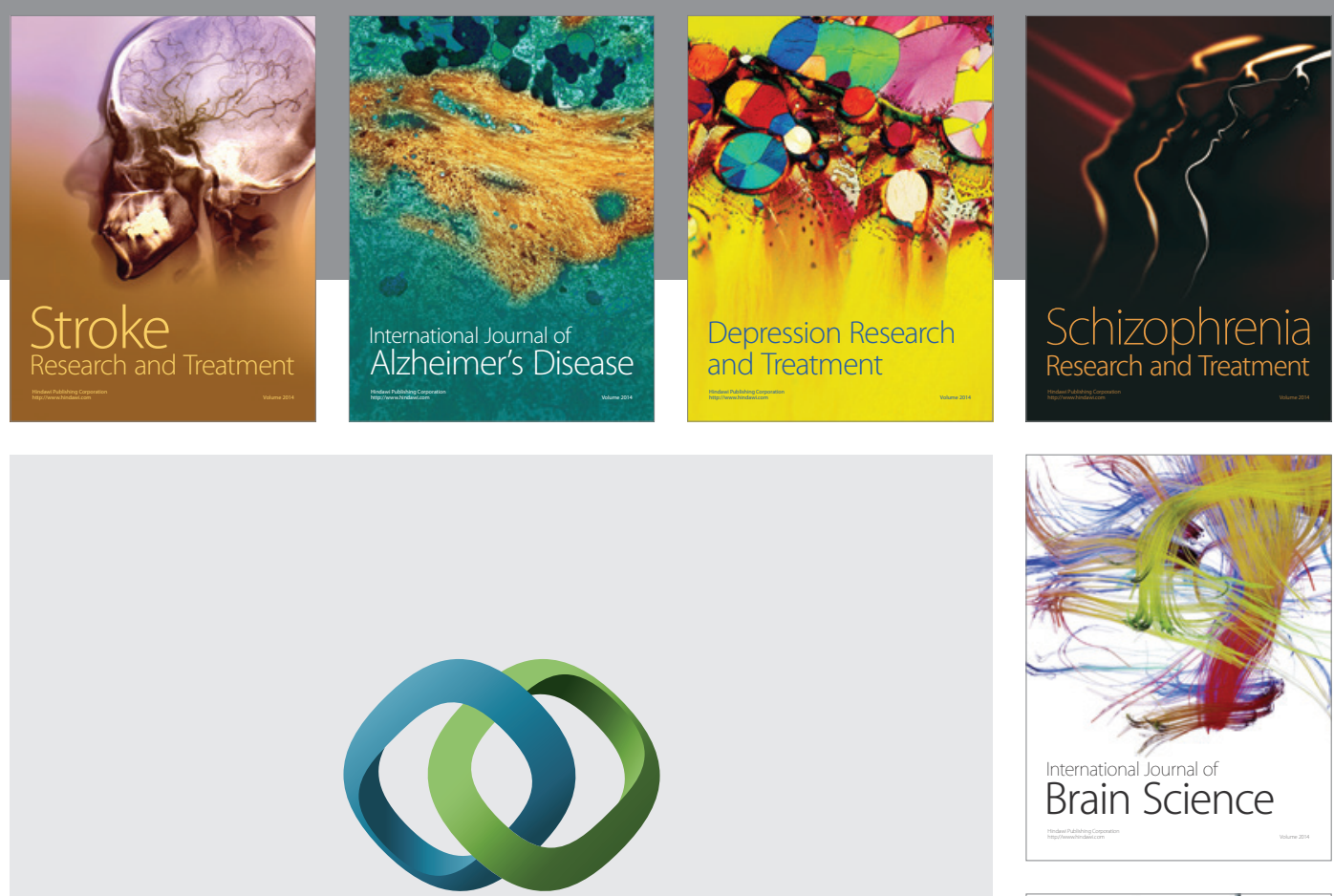

\section{Hindawi}

Submit your manuscripts at

http://www.hindawi.com
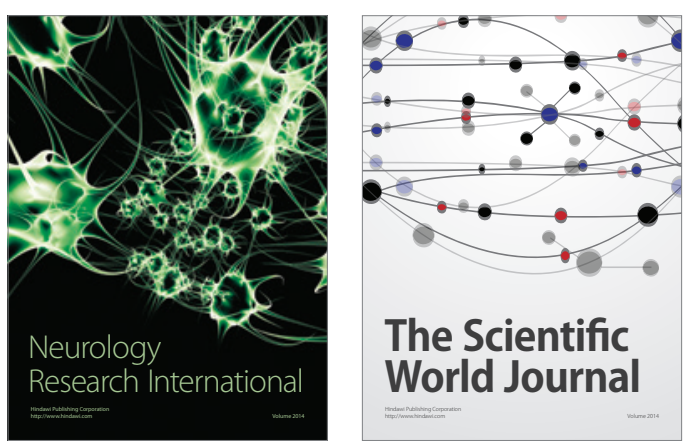

The Scientific World Journal

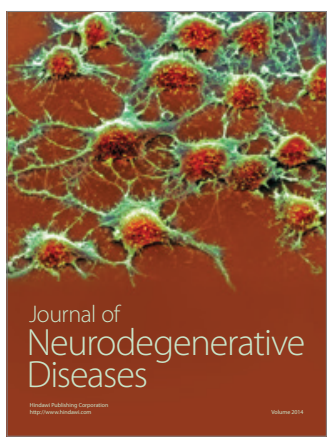

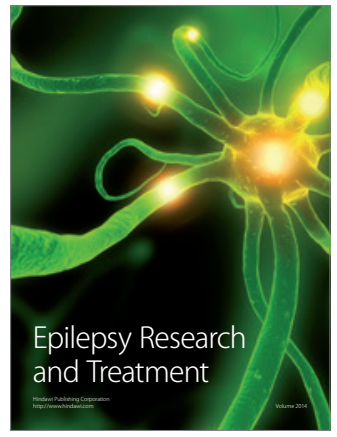

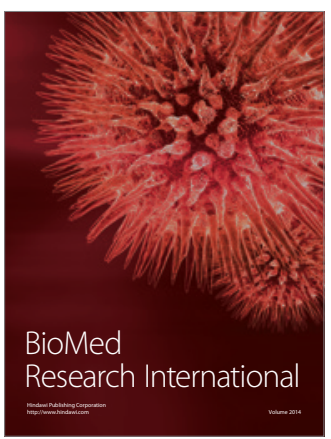

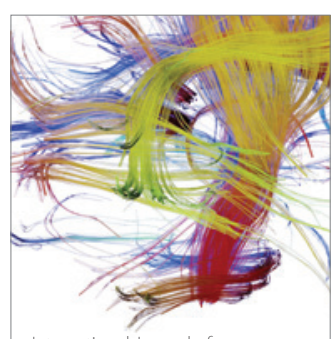

Brain Science

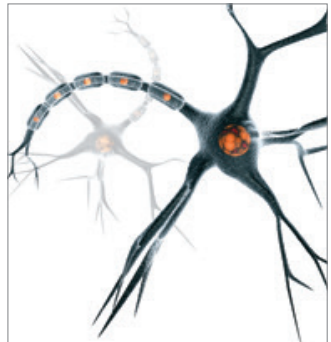

Neural Plasticity
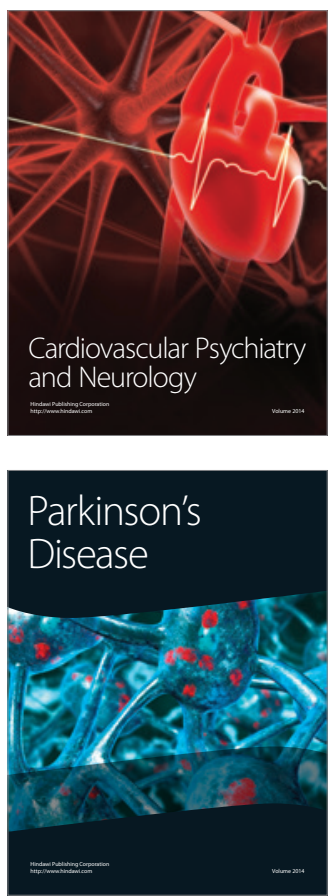